TRABAJOS DE PREHISTORIA

78 , N. ${ }^{\circ}$ 2, julio-diciembre 2021, pp. 237-256, ISSN: 0082-5638

https://doi.org/10.3989/tp.2021.12274

\title{
Font del Ros y el Neolítico Antiguo en el nordeste de la península ibérica*
}

\author{
Font del Ros and the early Neolithic in northeast Iberia
}

\author{
Rafael Labordaa, Jorge Martínez-Moreno ${ }^{a}$, Javier Plasencia Figueroa ${ }^{a}$, Paloma González \\ Marcén $^{\mathrm{a}}$ y Rafael Mora ${ }^{\mathrm{a}}$
}

\section{RESUMEN}

El estudio de los estilos decorativos cerámicos permite evaluar la aparición, dispersión y consolidación del Neolítico en la península ibérica. Font del Ros (Berga, Barcelona) es un enclave localizado al pie del Prepirineo oriental. Las informaciones preliminares allí obtenidas indican la presencia de una estructura de hábitat parcialmente preservada asociada con cerámicas con decoración cardial y 25 fosas, conteniendo otras que también remiten a la esfera del Neolítico Antiguo. Cinco fechas C14 AMS avalaban esta atribución. Estas inferencias relevantes que incentivaban el debate sobre la irrupción del Neolítico en el nordeste peninsular han tenido escasa repercusión. La conservación del conjunto cerámico no es óptima pero los estilos cardial e impreso-inciso son recurrentes en los restos decorados. Estos indicadores trazan conexiones con los desarrollos que se detectan en el litoral mediterráneo y el Prepirineo central (Lleida y Huesca), de los que Font del Ros dista más de $100 \mathrm{~km}$. Esta circunstancia permite examinar posibles interacciones con estas áreas geoculturales, y otras adyacentes transpirenaicas. Nuevas fechas sobre muestras de vida corta posicionan el conjunto entre 5420-5070 cal BC. Estos indicadores estilísticos y cronométricos inciden en el debate sobre el proceso relacionado con la aparición y consolidación del Neolítico Antiguo en el nordeste de la península ibérica.

\begin{abstract}
The study of ceramic decorative styles allows one to evaluate the appearance, dispersion and consolidation of the Neolithic in the Iberian peninsula. Font del Ros (Berga, Barcelona) is a site located at the foot of the eastern Pre-Pyrenees. Preliminary information is available indicating the
\end{abstract}

presence of a partially preserved habitat structure associated with ceramics with cardial decoration and 25 silos, also containing early Neolithic pottery. Five C14 AMS dates supported this attribution. These important inferences have had little impact on the debate on the emergence of the Neolithic in the northeast of the peninsula have had little impact. Although the conservation of the ceramic ensemble is not optimal, the cardial and printed-incised styles are recurrent in the decorated pottery. These indicators trace connections with the developments detected on the Mediterranean coast and the central Pre-Pyrenees (Lleida and Huesca), areas more than $100 \mathrm{~km}$ away from Font del Ros. This circumstance allows us to examine possible interactions with these geocultural areas and others north of the Pyrenees. New dates on shortlived samples place the Font del Ros assemblage between 5380-5060 cal BC. These stylistic and chronometric indicators contribute to the debate on the processes related to the appearance and consolidation of the early Neolithic in the northeast of the Iberian peninsula.

Palabras clave: Font del Ros; neolitización; Cardial; Epicardial; cronometría; nordeste de la península ibérica.

Key words: Font del Ros; neolithisation; Cardial; Epicardial; chronometry; northeast Iberia.

\section{DEBATES EN TORNO A LOS MODELOS DE NEOLITIZACIÓN EN EL NORDESTE DE LA PENÍNSULA IBÉRICA}

La aparición de plantas y animales domésticos junto a innovaciones técnicas con la cerámica como icono

\footnotetext{
* Este trabajo que analiza el significado del Neolítico Antiguo de Font del Ros se incluye en el proyecto "Asentamiento humano en el Pleistoceno final y Holoceno del sudeste de los Pirineos" (PID 2019-104843GB-I00, Ministerio de Ciencia e Innovación, Gobierno de España) del Grup de Reçerca 2017 SGR-1357 reconocido por la Agencia Gestió Ajust Universitaris i Reçerca de la Generalitat de Catalunya.

a Centre Estudis del Patrimoni Arqueològic-CEPARQ. Facultat de Lletres. Universitat Autònoma Barcelona. 08193 Bellaterra. Correos-e.: RL https://orcid.org/0000-0002-0925-6390; JMM jorge.martínez@uab.cat (autor de correspondencia) https://orcid.org/0000-0002-6326-7058; JPF https://orcid.org/0000-0002-2487-6811; PGM https://orcid.org/0000-0002-9410-8826; RM https://orcid.org/0000-0001-7824-6818

Recibido 15-I-2021; aceptado 3-VIII-2021.
}

Copyright: (C) 2021 CSIC. Este es un artículo de acceso abierto distribuido bajo los términos de la licencia de uso y distribución "Creative Commons Reconocimiento 4.0 Internacional" (CC BY 4.0) 
definen un nuevo sistema socio-organizativo que en pocas centurias se extiende prácticamente por toda la península ibérica. Este rápido proceso se ha vinculado con la irrupción de poblaciones pioneras foráneas que promueven la dispersión de estos bioproductos y artefactos, prevista por el modelo "ola de avance" (Ammerman y Cavalli-Sforza 1973). Sin embargo, la aparición y consolidación del Neolítico en la península ibérica sigue envuelta en diversas controversias (Bernabeu 1996; Jiménez Guijarro 2010; Cruz Berrocal 2012; Jover Maestre y García Atienzar 2014; GarcíaMartínez de Lagrán 2018, entre otros).

La construcción de un marco cronométrico que posicione la irrupción y propagación de este nuevo sistema es una vía para superar estas limitaciones, que tiene un papel destacado en esta discusión. La compilación de bases de datos cronométricos depura anomalías e identifica tendencias generales de las que derivan trayectorias temporales fiables y precisas para reconstruir este proceso (Balsera et al. 2015; García-Puchol et al. 2018; Pardo-Gordó et al. 2019, Martínez-Grau et al. 2021, entre otros).

Esos rangos temporales permiten proponer que la instalación de poblaciones alóctonas por el litoral de la península ibérica configura "focos" implicados en la irradiación de esas innovaciones con la cerámica con decoración cardial como icono. Esta perspectiva subraya la prioridad temporal de esas poblaciones exógenas, claves en la propagación del Neolítico por el interior (Zilhão 1997, 2001; Martins et al. 2015; Isern et al. 2017). Sin embargo, la aparición de estas innovaciones, con rangos temporales ligeramente más recientes, en zonas periféricas como el Prepirineo central (Huesca y Lleida), advierte de rutas alternativas por las que transitaron esas novedades (Utrilla et al. 1998; Rojo et al. 2006, 2018; Alday 2009; Baldellou 2011; García Martínez de Lagrán 2018, entre otros). Aunque estas perspectivas no son necesariamente incompatibles, reabren la discusión al referir la neolitización bien como un proceso unilineal guiado por las poblaciones instaladas el litoral, bien como un desarrollo donde confluyen y/o participan varias entidades culturales.

Nuevos datos contextuales, materiales y radiométricos provenientes del nordeste de la península ibérica, zona con una activa tradición investigadora, revitalizan este debate, al proponerse una precoz irrupción neolítica en dos "focos": el área "clásica" del litoral mediterráneo, y el Prepirineo central (Huesca y Lleida) (Oms 2014; Oms 2017; García Martínez de Lagrán 2018; Guilaine 2018; Rojo et al. 2018; Laborda 2019, entre otros). En la identificación de estas áreas geoculturales es clave la redefinición de estos estilos decorativos cerámicos, explicitada en Bernabeu et al. (eds) (2011).
En esta reflexión, la fase de Font del Ros entre 5500-5000 cal BC con decoraciones cerámicas adscritas al Neolítico Antiguo ha pasado muy desapercibida (Bordas et al. 1996; Pallarés et al. 1997; Roda et al. 2018). La revisión de los estilos decorativos del conjunto cerámico, y su contextualización con una nueva serie de fechas C14 AMS sobre muestras de vida corta, permite analizar la inserción de Font del Ros en relación con la aparición del Neolítico en el nordeste de la península ibérica (Oms et al. 2016a; Oms 2017).

\section{FONT DEL ROS: UN ASENTAMIENTO EN EL PREPIRINEO ORIENTAL}

Font del Ros se localiza en el Plà de l'Alemany (31 ETRS89 X5232439,43, Y263591,23) a $680 \mathrm{~m} \mathrm{~s}$. n. m., llanura aluvial por la que discurre el río Llobregat al pie de la Serra de Queralt (1588 m s. n. m.), la primera estibación del Prepirineo oriental de Barcelona (Fig. 1).

En 1988 Josep Carreras de la Secció d'Arqueología del Museu de Berga (Barcelona) advirtió de los abundantes vestigios arqueológicos aparecidos en un solar de $1700 \mathrm{~m}^{2}$, destinado a la construcción de viviendas dentro del municipio. Ante el riesgo de su inminente destrucción, el Servei d'Arqueología de la Generalitat de Catalunya autorizó varias fases de excavación. Bajo la coordinación de uno de los firmantes (R. M.), entre 1988 y 1991 se conformaron varios equipos de dirección responsables de recuperar, gestionar y conservar este relevante conjunto arqueológico. La intervención implicaba novedosos retos en un momento en el que experiencias relacionadas con la ejecución de intervenciones de esta magnitud eran escasas.

El estudio geoarqueológico de la secuencia de $5 \mathrm{~m}$ potencia, identifica en su parte superior dos unidades arqueológicas que remiten a fases cronoculturales distintas que corresponden con un nivel inferior -SG- que se extiende por $1200 \mathrm{~m}^{2}$ y contiene ocupaciones adscritas al Mesolítico (entre 8600-6500 cal BC) (Roda et al. 2016, 2018); la unidad superior $-\mathrm{N}$ - atribuida al Neolítico Antiguo, se caracteriza a continuación. Entre estos eventos se desarrolla un paquete sedimentario de $0,5 \mathrm{~m}$ de espesor arqueológicamente estéril (Jordà et al. 1992), que señala una distancia radiométrica aproximada de 900 años (Martínez-Moreno et al. 2006).

La excavación sobre el solar configura un trapezoide irregular de $60 \times 40 \mathrm{~m}$ de superficie. Antes y durante la misma, las obras de edificación destruyeron parte del registro arqueológico. Las unidades arqueológicas SG y N superan los límites laterales del área excavada en todas direcciones. Esta circunstancia, común en los sitios al aire libre, dificulta fijar la extensión del asentamiento. 

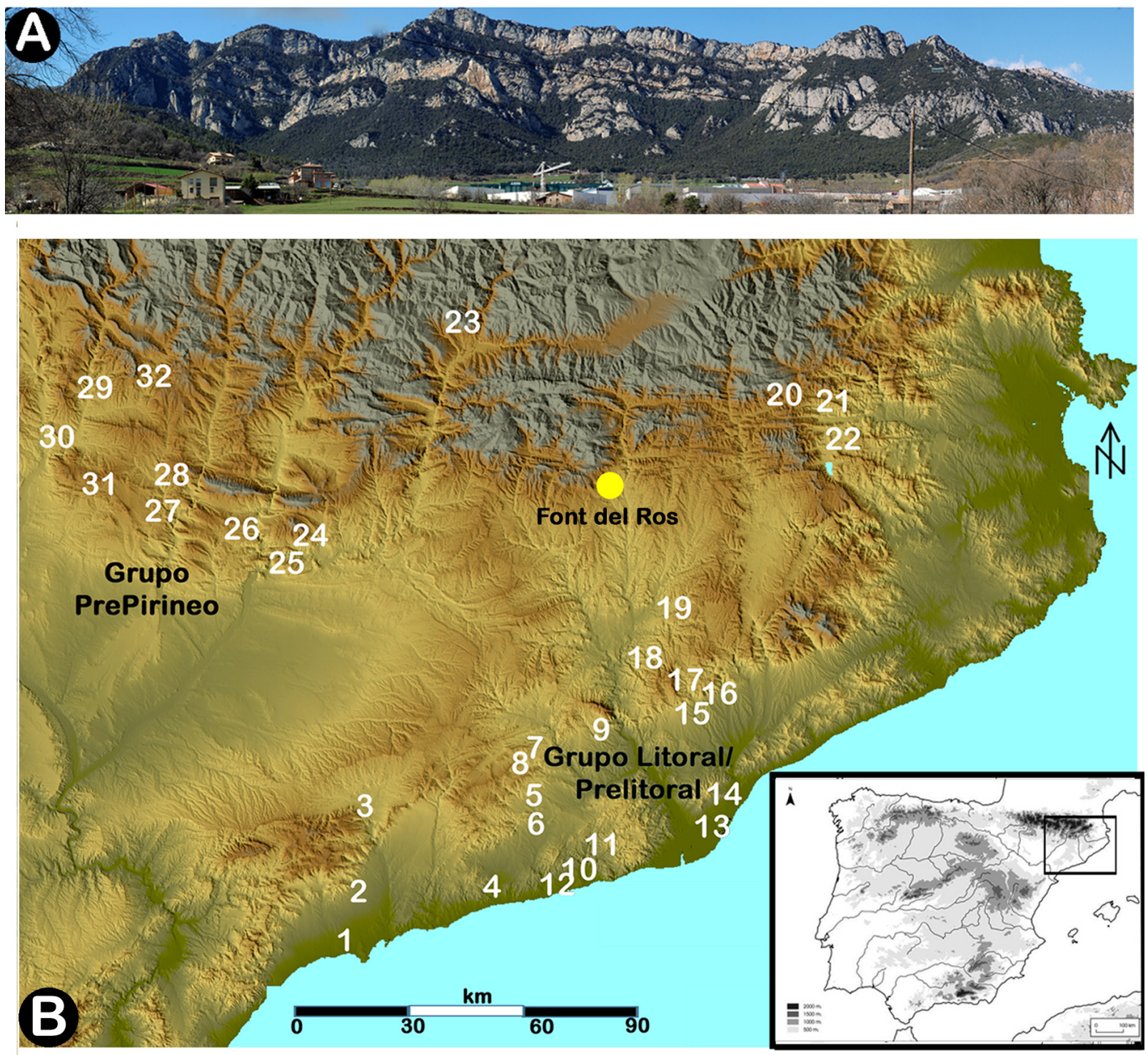

Fig. 1. A. En primer término, el contacto entre la llanura aluvial del Plà de l’Alemany donde se sitúa Font del Ros (Berga, Barcelona) y La Serra de Queralt (Prepirineo de Barcelona). B Localización de Font del Ros respecto a las dos áreas geoculturales del Neolítico Antiguo del nordeste de la península ibérica. "Grupo del Litoral/Prelitoral mediterráneo": 1. Cavet; 2. Coll Blanc; 3. Cova Font Major; 4. Cova Foradada; 5. Guixeres de Vilobí; 6. La Serreta; 7. Cova de la Guineu y Cova del Bolet; 8. Esquerda de les Roques del Pany; 9. Cova Gran y Cova Freda; 10. Cova de Can Sadurní; 11. Cova Bonica, 12. Cova de Sant Llorenç; 13. Sant Pau del Camp; 14. Plaça Vila de Madrid; 15. Can Roqueta II; 16. Turó de Can Bellsolà; 17. Cova del Frare; 18. Balma de l'Espluga; 19. Cova del Toll; 20. Balma del Serrat del Pont; 21. Plansallosa; 22. La Draga y Coves del Reclau Viver. "Grupo del Prepirineo central": 23. Balma Margineda; 24. Cova del Parco; 25. Abric del Xicotó; 26. Cova Gran de Santa Linya; 27. Joan d'Os; 28. Cova Colomera; 29. Puyascada y Forcón; 30. Chaves; 31. Cueva de Olvena; 32. Els Trocs. Margineda y Chaves contienen materiales atribuidos a la esfera cardial. Mapa derivado de la Ortofoto de Catalunya 1:250.000 del Institut Cartogràfic i Geològic de Catalunya (ICGC), utilizada bajo una licencia CC BY 4.0. En color en la versión electrónica. 


\section{ESPACIOS Y CONTEXTOS DEL NEOLÍTICO ANTIGUO EN FONT DEL ROS}

La unidad N adscrita al Neolítico Antiguo se reconoce sobre dos zonas con implicaciones distintas a nivel temporal, espacial y contextual: Suelo Neolítico (Suelo N) y el campo de fosas (Bordas et al. 1996) (Fig. 2).

\subsection{El Suelo $\mathbf{N}$}

Esta unidad se extiende por una superficie de $30 \times 3$ $\mathrm{m}$ (coordenadas de cuadrícula $\mathrm{x}=45-75, \mathrm{y}=53-49$ ) y se corresponde con una zona marginal adosada al límite norte de la excavación. Se excavaron dos banquetas discontinuas afectadas por las obras, desapareciendo por debajo del eje $\mathrm{y}=49$, aunque posiblemente supera el límite establecido por la pared norte del solar (Fig. 2). Se recuperaron restos líticos y cerámicos en un nivel sedimentario con escasa dispersión vertical $(5 \mathrm{~cm})$ de espesor, una acumulación que remite a la noción de "suelo de ocupación" (Bordes 1975). Varios fragmentos cerámicos con decoración cardial (detallados más adelante) se asociaban a una datación C14 AMS sobre carbón. La fecha $6561 \pm 56$ BP (AA 16498) permitía relacionarlo con un evento inicial del Neolítico Antiguo (Bordas et al. 1996; Pallarés et al. 1997). En esos ámbitos se reconocieron elementos referidos a la organización interna del espacio y en la banqueta $E$ (entre $x=45-60, y=51$ 52) como 3 depresiones de $30-40 \mathrm{~cm}$ de diámetro, con sección cónica y $20 \mathrm{~cm}$ de profundidad, separadas regularmente en torno a un metro. Estos agujeros de poste advierten de un elemento arquitectónico perecedero de grandes dimensiones, marginalmente preservado (Bordas et al. 1996; Jover Maestre et al. 2019) (Fig. 3a).

\subsection{El campo de fosas}

A lo largo de $1050 \mathrm{~m}^{2}$, entre los ejes de coordenadas $\mathrm{x}=20-55 \mathrm{y}=01-30$, se identificaron 45 estructuras negativas, 9 de ellas sin ningún tipo de material (Fig. 2). Estas fosas de planta circular/ovalada tienen diámetros entre 1-1,50 m, sección troncocónica y base plana (Bordas et al. 1996). La mayoría están extremadamente arrasadas, conservando el perímetro basal con escaso

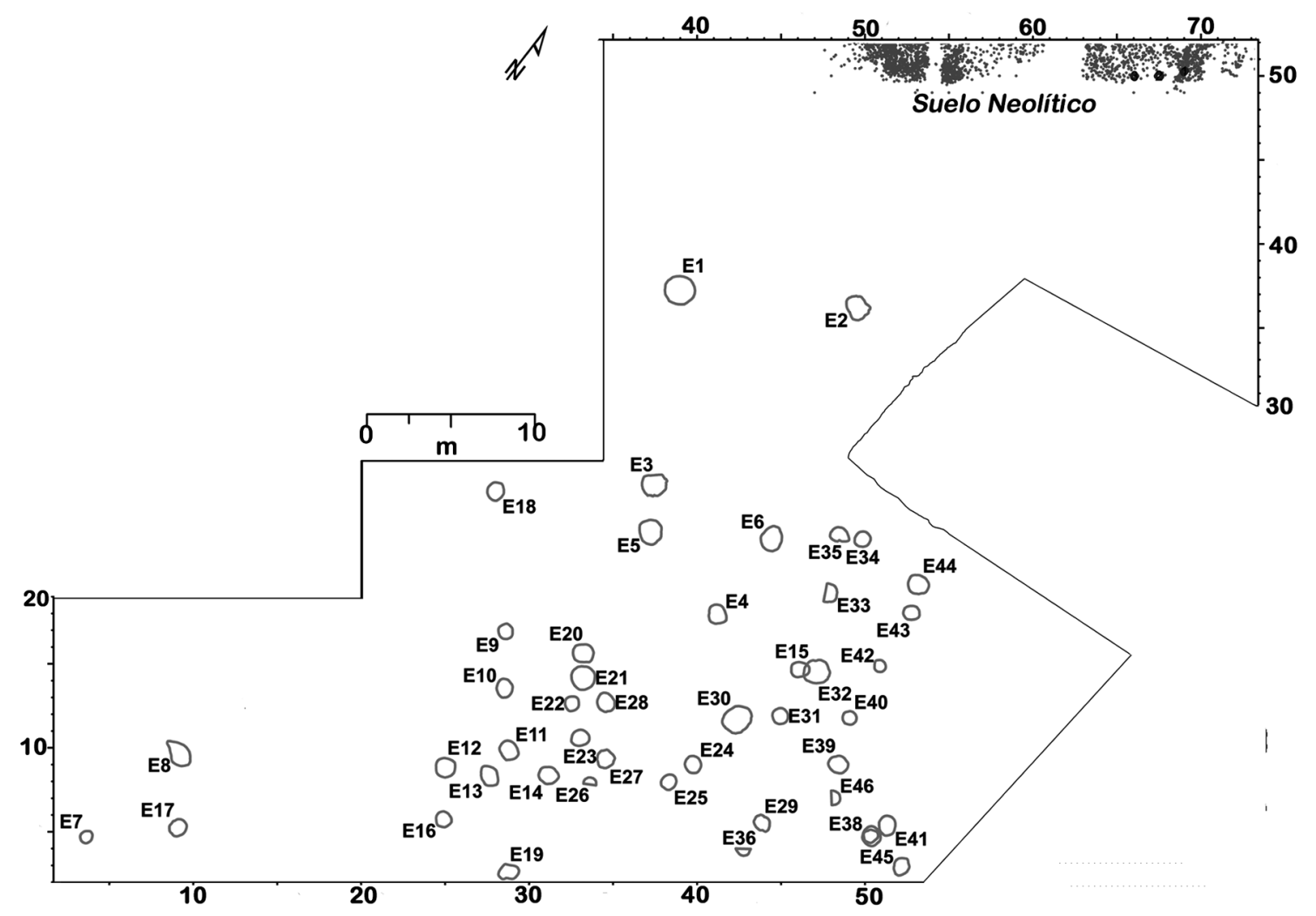

Fig. 2. Font del Ros (Berga, Barcelona) Unidad Neolítica. En la zona norte se proyectan los coordenados y los agujeros de poste del Suelo Neolítico (coordenadas $\mathrm{X}=67-69 / \mathrm{Y}-50$. Ver figura $3 \mathrm{~A}$ ). Los ejes $\mathrm{X}=25-55 / \mathrm{Y}=0-30$ concentran la mayoría de las fosas.

Trab. Prehist., 78, N. ${ }^{\circ} 2$, julio-diciembre 2021, pp. 237-256, ISSN: 0082-5638 https://doi.org/10.3989/tp.2021.12274 
desarrollo vertical (entre $20-40 \mathrm{~cm}$ de potencia). Frente a lo señalado recientemente (Prats et al. 2020) esto dificulta calcular su potencial capacidad de almacenaje. No se mencionan posibles fases de uso y/o reutilización excepto en E-33 donde se diferenciaron dos niveles de acumulación. En E-27, E-36 y E-39 se advierte el vertido de residuos de combustión ${ }^{1}$. Se puede asumir que su colmatación es el resultado del depósito y/o de un nuevo depósito de artefactos y ecofactos que configuran acumulaciones heterogéneas, asociadas fortuitamente por eventos que se escalonan durante un rango tempo-

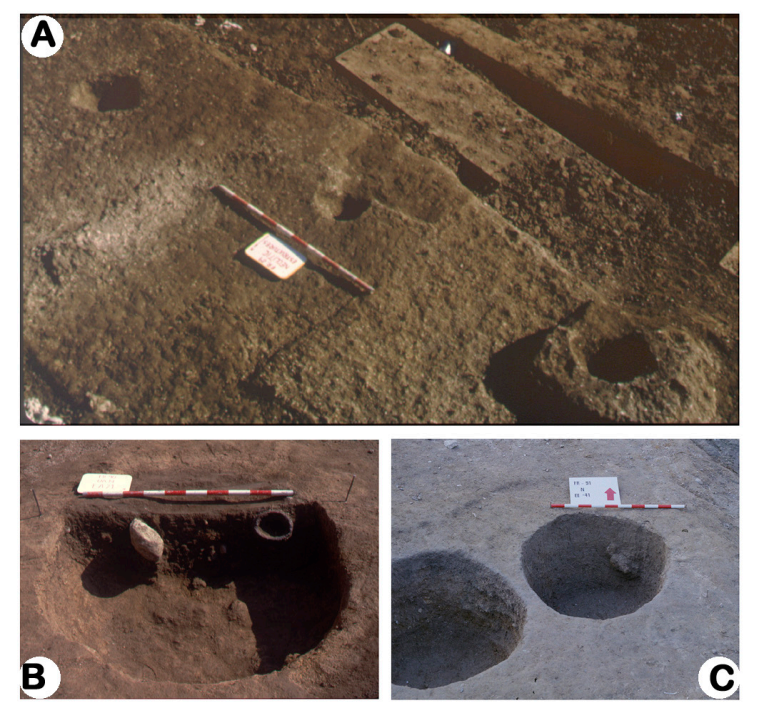

Fig. 3. Font del Ros (Berga, Barcelona). A. Suelo Neolítico: depresiones circulares de pequeño diámetro alineadas atribuidas a una estructura constructiva parcialmente conservada; contenedor B. fosa E-21 muy arrasada y con escaso sedimento que contiene un molino y el vaso 15 (Fig. $5 \mathrm{G}$ ); contenedor C. fosas E-41 y E-38 representativas del conjunto. En color en la versión electrónica.

ral impreciso (Blanco González 2016). Pese a que estos palimpsestos afectan a la caracterización cronocultural de estos conjuntos, sin embargo, el tamaño de las fosas permite proponer que esos rellenos no indican intervalos temporales prolongados (Fig. $3 \mathrm{~b}$ y $3 \mathrm{c}$ ).

Este artículo no pretende catalogar en detalle los conjuntos recuperados en cada contenedor, alternativamente se caracterizan brevemente las principales categorías representadas. La composición fisicoquímica del sedimento puede estar detrás de la práctica ausencia de restos óseos (Jordá et al. 1992). Habitualmente,

1 R. Mora Torcal (coord.). Font del Ros (Berga). Informe entregado al Servei d'Arqueologia. Dept. de Cultura-Generalitat de Catalunya. Universitat Autónoma de Barcelona, 1991. las fosas contienen pocos materiales y los artefactos se abandonan tras un intenso uso, como indica el instrumental de molienda (molinos y manos). En el estudio carpológico se mencionan fragmentos de avellana y bellota en 2 fosas, siendo muy significativo que en 14 contenedores se identifiquen semillas carbonizadas de Hordeum vulgare y Triticum dicoccum -en menor medida T. aestivum/durum y T. monococcum-, son variedades ajustadas a las condiciones ecológicas frías y húmedas prevalentes en la zona ${ }^{2}$ (Antolín 2013). Estos cereales aparecen segregados en fosas distintas, excepto en E-40 que contenía semillas de trigo y cebada. Ello se consideró un posible indicador de pautas agrícolas diferenciadas quizás con implicaciones de orden temporal (Pallarés et al. 1997). Esta alternativa es difícil de evaluar debido al reducido tamaño de estas muestras, aunque cereales y artefactos de molienda atestiguan el cultivo de cereales. Aunque los restos cerámicos están mal conservados, en 15 contextos remiten a la esfera cardial y otros 10 al horizonte epicardial (Bordas et al. 1996). Estas observaciones preliminares relativas a aspectos claves de la organización del asentamiento merecerán ser ampliadas en futuros estudios.

\subsection{Resignificando la Unidad $\mathrm{N}$ a nivel organizativo, contextual y cultural}

Los trabajos de edificación sobre el solar y la posible extensión del Suelo $\mathrm{N}$ más allá de los límites de la excavación dificultan evaluar su significado. La noción de "suelo de ocupación" refiere a la asociación de restos líticos y cerámicos en un contexto sedimentario con una baja dispersión vertical, en el que no se reconocen procesos naturales de transporte que propicien su acumulación y asociación. Sin embargo, los 3 agujeros de poste excavados sobre banqueta advierten de una construcción residual que contenía artefactos, destacando varios fragmentos cerámicos con decoración cardial.

Los materiales amortizados en las fosas indican distintos usos. Los conjuntos con pocas semillas recuperados en los 14 contenedores remiten al almacenaje de cereales, actividad confirmada por la presencia de instrumental relacionado con la molienda. El abocamiento de cerámicas, instrumental lítico y residuos alimentarios conforma asociaciones no estrictamente sincrónicas, pero la información disponible no sugiere colmataciones dilatadas en amplios intervalos temporales.

Es difícil establecer la relación temporal entre el Suelo $\mathrm{N}$ y las fosas, separadas por más de $25 \mathrm{~m}$ de distancia, así como la conexión espacial entre los contene-

\footnotetext{
${ }^{2}$ V. López Morillas. Informe técnico: estudio paleocarpológico Font del Ros. Campañas excavación 1989, 1990, 1991. Universitat Autònoma de Barcelona, 1993, inédito.
} 
dores. Las decoraciones cerámicas señalan 25 contextos relacionados con el Neolítico Antiguo. Esta atribución cronocultural confirmada por la serie $\mathrm{C} 14$ advierte de una extensa diacronía (5600-4800 cal BC). Estas conclusiones subrayan la relevancia del asentamiento de Font del Ros en la discusión del Neolítico Antiguo del nordeste de la península ibérica (Bordas et al. 1996; Pallarés et al. 1997). Este argumento puede examinarse a partir de la revisión de los estilos decorativos cerámicos y de la cronometría del asentamiento, aspectos claves para analizar la incidencia de este asentamiento.

\section{EL CONJUNTO CERÁMICO DE FONT DEL ROS}

La elevada fragmentación del conjunto cerámico dificulta identificar tamaños, formas y técnicas de elaboración, por lo que el análisis se ha focalizado en los restos cuyos atributos morfométricos y decorativos permiten individualizar vasos específicos. Hay 1.213 fragmentos: 494 proceden del Suelo N y 719 de 36 fosas. Se ha determinado un mínimo de 53 vasos con diferentes grados de conservación. Se recuperó solo un vaso completo muy deformado (n. ${ }^{\circ} 15$ de E-21, Fig. 4G) y 3 parciales (n. ${ }^{\circ} 4$ de E-3, Fig. $4 \mathrm{~L} ;$ n. $^{\circ} 12$ de E-15, Fig. 5C; n. ${ }^{\circ} 23$ de E-28, Fig. 5A). La atribución formal del resto de vasos se hizo a partir de pequeños fragmentos decorados, a veces muy erosionados.

\subsection{Indicadores tecno-morfológicos}

El tamaño de los restos dificulta, pero no impide advertir tendencias morfométricas. Dominan las piezas con perfil cerrado y globular, frente a cuencos hemisféricos de perfil recto. Las formas abiertas son escasas. Es complicado identificar recipientes ovoides de fondo profundo por el escaso desarrollo de los perfiles y posiblemente han quedado integrados en otras categorías. No se han diferenciado botellas, aunque dos fragmentos cóncavos podrían corresponder a formas de cuello destacado. Algunos restos con parte del perfil y/o contorno, cuya morfología se desconoce, se individualizaron a partir de su decoración. Solo el vaso 15 (E-21) conserva la base redondeada, marcada por un engrosamiento de la pared que difiere del que tiene el cuerpo del recipiente. Entre los fragmentos de fondo no aparecen formas cónicas o planas. La mayoría de las bases son redondeadas o ligeramente engrosadas, indiferenciables de las paredes.

A partir del diámetro del borde o de extrapolar el tamaño de los recipientes a partir del grosor de los fragmentos, se contabilizan al menos 8 recipientes pequeños (diámetros inferiores a $15 \mathrm{~cm}$ ), 12 medianos (entre 15 y $20 \mathrm{~cm}$ ) y 10 grandes (más de $20 \mathrm{~cm}$ ). La fragmentación del conjunto dificulta asignar tamaños y formas. Los cuencos hemisféricos suelen ser recipientes pequeños, los medianos tienden a ser globulares, mientras los grandes se relacionan con formas ovoides. No se reconocen recipientes hemisféricos con amplio diámetro y escaso fondo (Tab. 1).

\begin{tabular}{|c|c|c|c|c|c|}
\hline & Peq. & Med. & Gran.. & Indet. & TOTAL \\
\hline Hemisférico & 6 & 3 & 3 & & 12 \\
\hline Globular & 2 & 9 & 3 & & 14 \\
\hline Ovoide & & & 4 & & 4 \\
\hline Indet. & & & & 23 & 23 \\
\hline TOTAL & 8 & 12 & 10 & 23 & $\mathbf{5 3}$ \\
\hline
\end{tabular}

Tab. 1. Font del Ros (Berga, Barcelona). Tendencias morfométricas de los vasos cerámicos decorados. Indet. diámetro indeterminado. Peq.: pequeños; Med.: medianos; Gran.: grandes; Indet.: indeterminados.

La atmósfera de cocción, los acabados y desgrasantes de los fragmentos decorados indican el dominio de cocciones irregulares $(50,9 \%)$ y oxidantes $(43,4 \%)$, frente a ambientes reductores $(5,7 \%)$. Las superficies erosionadas (45,3\%) complican la definición de los acabados. Están presentes el alisado (32,1\%) y el bruñido/ espatulado $(22,5 \%)$. Las superficies bruñidas o espatuladas que han perdido el lustre se clasificaron como alisadas. Este atributo redunda en la noción de una generalizada mala conservación del conjunto (Tab. 2).

\begin{tabular}{|c|c|c|c|c|c|c|c|}
\hline \multirow{2}{*}{ Cocciones } & \multicolumn{2}{|c|}{ Oxidante } & \multicolumn{2}{|c|}{ Reductora } & \multicolumn{2}{|c|}{ Irregular } & Total \\
\hline & 23 & $43,3 \%$ & 3 & $5,7 \%$ & 27 & $50,9 \%$ & \\
\hline \multirow{2}{*}{ Acabados } & \multicolumn{2}{|c|}{ Alisado } & \multicolumn{2}{|c|}{$\begin{array}{l}\text { Bruñido- } \\
\text { espatulado }\end{array}$} & \multicolumn{2}{|c|}{ Erosionado } & \\
\hline & 17 & $32,1 \%$ & 12 & $22,6 \%$ & 24 & $45,3 \%$ & \\
\hline \multirow{2}{*}{$\begin{array}{l}\text { Tipo des- } \\
\text { grasante }\end{array}$} & \multicolumn{2}{|c|}{ Mica-cuarzo } & \multicolumn{2}{|c|}{ Cuarzo } & \multicolumn{2}{|c|}{$\begin{array}{l}\text { Calcita- } \\
\text { cuarzo }\end{array}$} & \\
\hline & 18 & $34 \%$ & 4 & $7,5 \%$ & 31 & $58,5 \%$ & \\
\hline \multirow{2}{*}{$\begin{array}{c}\text { Tamaño } \\
\text { desgrasante }\end{array}$} & \multicolumn{2}{|c|}{ Fino } & \multicolumn{2}{|c|}{ Medio } & \multicolumn{2}{|c|}{ Grueso } & \\
\hline & 14 & $26,4 \%$ & 21 & $39,6 \%$ & 18 & $34 \%$ & \\
\hline \multirow{2}{*}{ Grosor } & \multicolumn{2}{|c|}{$\leq 6 \mathrm{~mm}$} & \multicolumn{2}{|c|}{$7.8 \mathrm{~mm}$} & \multicolumn{2}{|c|}{$\geq 9 \mathrm{~mm}$} & \\
\hline & 3 & $5,7 \%$ & 24 & $45,3 \%$ & 26 & $49,1 \%$ & 53 \\
\hline
\end{tabular}

Tab. 2. Font del Ros (Berga, Barcelona). Cocción, acabados, desgrasante y grosor de la pared de las cerámicas decoradas (frecuencias absolutas y relativas).

Según el análisis macroscópico de desgrasantes en más de la mitad de los recipientes el componente más abundante de la pasta es la calcita mezclada con cuarzo 

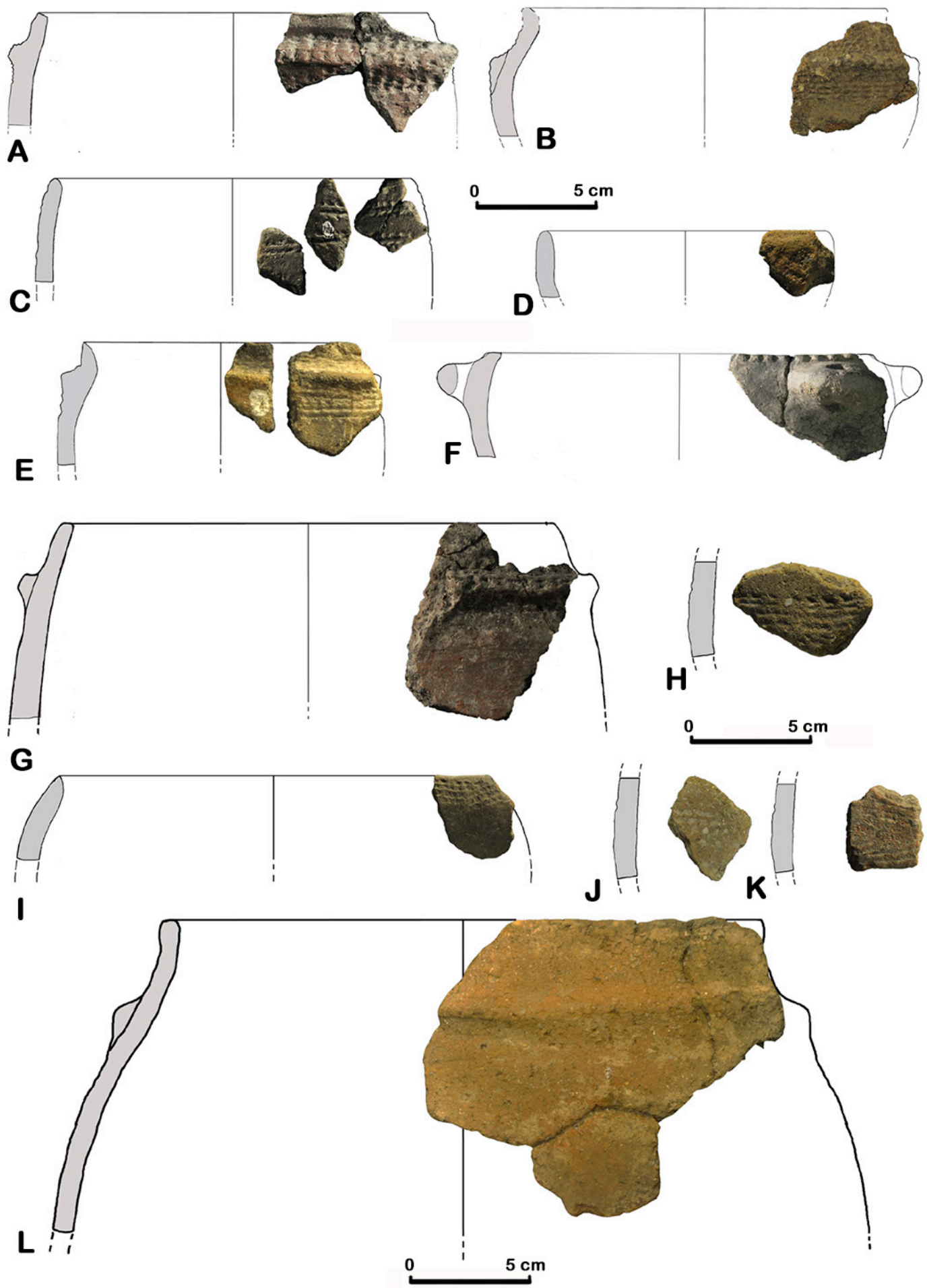

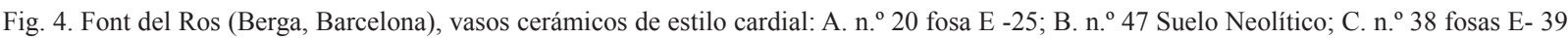
y E-42; D. n. ${ }^{\circ} 49$ Suelo Neolítico; E. n. ${ }^{\circ} 22$ fosa E-27; F. n. ${ }^{\circ} 26$ E-32; G. n. ${ }^{\circ} 27$ fosa E-32; H. n. ${ }^{\circ} 36$ fosa E-38; I. n. ${ }^{\circ} 39$ E-40; J. n. ${ }^{\circ} 21$ fosa E-25; K. n. ${ }^{\circ} 43$ fosa E-43; L. n. ${ }^{\circ} 4$ fosa-E 3. En color en la versión electrónica. 
(58,5\%). La combinación mica y cuarzo (34\%) podría resultar de la disgregación de cantos de granito, o de la captación de depósitos arcillosos con un alto componente granítico, habitual en los ríos pirenaicos (Lapuente e Igea 2014). El cuarzo como desgrasante único aparece en 4 fragmentos (7,5\%).

\subsection{Estilos decorativos}

Los motivos decorativos de las cerámicas del Suelo $\mathrm{N}$ y fosas identifican al menos 53 vasos, siendo un conjunto relevante dentro del Neolítico Antiguo del nordeste de la península ibérica. Los estilos reconocidos son la impresión cardial, la impresión no cardial, incisiones, cordones lisos o impresos, que se combinan generando decoraciones impreso-incisas e impresióncordón (Tab. 3).

\begin{tabular}{|c|c|c|}
\hline Técnicas decorativas & $\mathrm{N}$ & $\%$ \\
\hline Cardial oblicuo & 4 & 7,5 \\
\hline Impresión múltiple & 4 & 7,5 \\
\hline Impresión simple sucesiva instrumento & 12 & 22,6 \\
\hline Impresión digitación + ungulación & 2 & 3,8 \\
\hline Cordón liso & 12 & 22,6 \\
\hline Cordón impreso & 7 & 13,2 \\
\hline Incisión & 6 & 11,3 \\
\hline Total simples & $\mathbf{4 7}$ & $\mathbf{8 8 , 7}$ \\
\hline Cardial oblicuo + cordón & 4 & 7,5 \\
\hline Impresión múltiple + cordón & 1 & 1,9 \\
\hline Impreso-inciso & 1 & 1,9 \\
\hline Total combinadas & $\mathbf{6}$ & $\mathbf{1 1 , 3}$ \\
\hline Total & $\mathbf{5 3}$ & $\mathbf{1 0 0}$ \\
\hline
\end{tabular}

Tab. 3. Técnicas decorativas identificadas en las cerámicas de Font del Ros

Las técnicas decorativas cardiales del litoral mediterráneo (Bernabeu 1989; Gómez Pérez 2011; Oms 2017; García Borja 2017, entre otros) y de algunos enclaves del Prepirineo central (Utrilla y Laborda 2018; Laborda 2019) presentan cierta diversidad. La impresión cardial oblicua, al grabar la pasta con una concha con un amplio abanico de ángulos, es habitual en Font del Ros al igual que en el nordeste peninsular (Bernabeu et al. 2011), mientras el cardial perpendicular está ausente (Fig. 4). La decoración cardial oblicua aparece en cuatro recipientes y combinada sobre cordón aplicado en otros cuatro. La mala conservación de los fragmentos dificulta reconocer las decoraciones reali- zadas con peine, integradas en la categoría impresión cardialoide (Moral del Hoyo y Cebrià 2006; Jiménez Guijarro 2010). Se consideran impresiones múltiples genéricas las aplicadas con un instrumento no identificable generando motivos que imitan los realizados con concha.

El otro grupo significativo son las decoraciones de estilo impreso-inciso (Fig. 5). En 4 recipientes se identifican impresiones. En otro se aplica un instrumento apuntado sobre el cordón, mientras que dos fragmentos presentan impresiones con un útil apuntado. En 6 de los 12 vasos, las impresiones se localizan sobre el borde del recipiente. La mayoría de los cordones son de sección semicircular, aunque dos con sección cuadrada y tres con tendencia triangular podrían considerarse crestas. En 12 recipientes con cordones lisos y 7 con impresiones sobre el cordón se aplicó o un instrumento o digitaciones. En 6 fragmentos las incisiones generan surcos estrechos relativamente profundos que no son los acanalados habituales del último tercio del VI milenio $\mathrm{BC}$, generalmente asociados con la decoración boquique (Alday 2009; García Martínez de Lagrán et al. 2011), estilo ausente en Font del Ros. El motivo impreso-inciso del vaso 6 (Fig. 5D) es habitual en el Neolítico pirenaico y en el interior peninsular (Oms et al. 2013; Rojo et al. 2013; Utrilla y Laborda 2018).

La adaptación del repertorio de técnicas y motivos decorativos, propuesta por Oms $(2014,2017)$ a partir del catálogo establecido para el Neolítico Antiguo del Mediterráneo occidental (Manen 2002), permite reconocer en Font del Ros 7 tipos sencillos y 2 complejos (Fig. 6). Los motivos más repetidos son los sencillos como la franja simple en disposición horizontal (A1) presente en 18 vasos o la formada por un cordón aplicado con o sin impresiones (I1) en 17 casos. La franja horizontal con cordón integrado (F1) y las franjas simples paralelas (B1) aparecen en 4 vasos, los cordones paralelos (I2) en 3 y la franja ancha (E1) en 2. Los motivos complejos componen guirnaldas descendentes (D3, D4) o combinan motivos simples. Una composición inédita en los catálogos citados pero que no desentona en este conjunto decorativo es la del vaso 15 (Fig. $5 \mathrm{G})$ : dos largas franjas verticales rellenas de incisiones convergentes, cortas, paralelas entre sí y perpendiculares a las franjas descendentes.

\section{AMPLIANDO LA RESOLUCIÓN CRONOMÉTRICA DE LA UNIDAD N}

La serie C14 AMS obtenida en los años 90 señalaba un rango temporal entre 5600-4800 cal BC, coincidente con la extensión temporal del Neolítico Antiguo en el nordeste de la península ibérica. Las fechas obtenidas en las fosas E-36, E-33, E-15 y E-21 fueron 

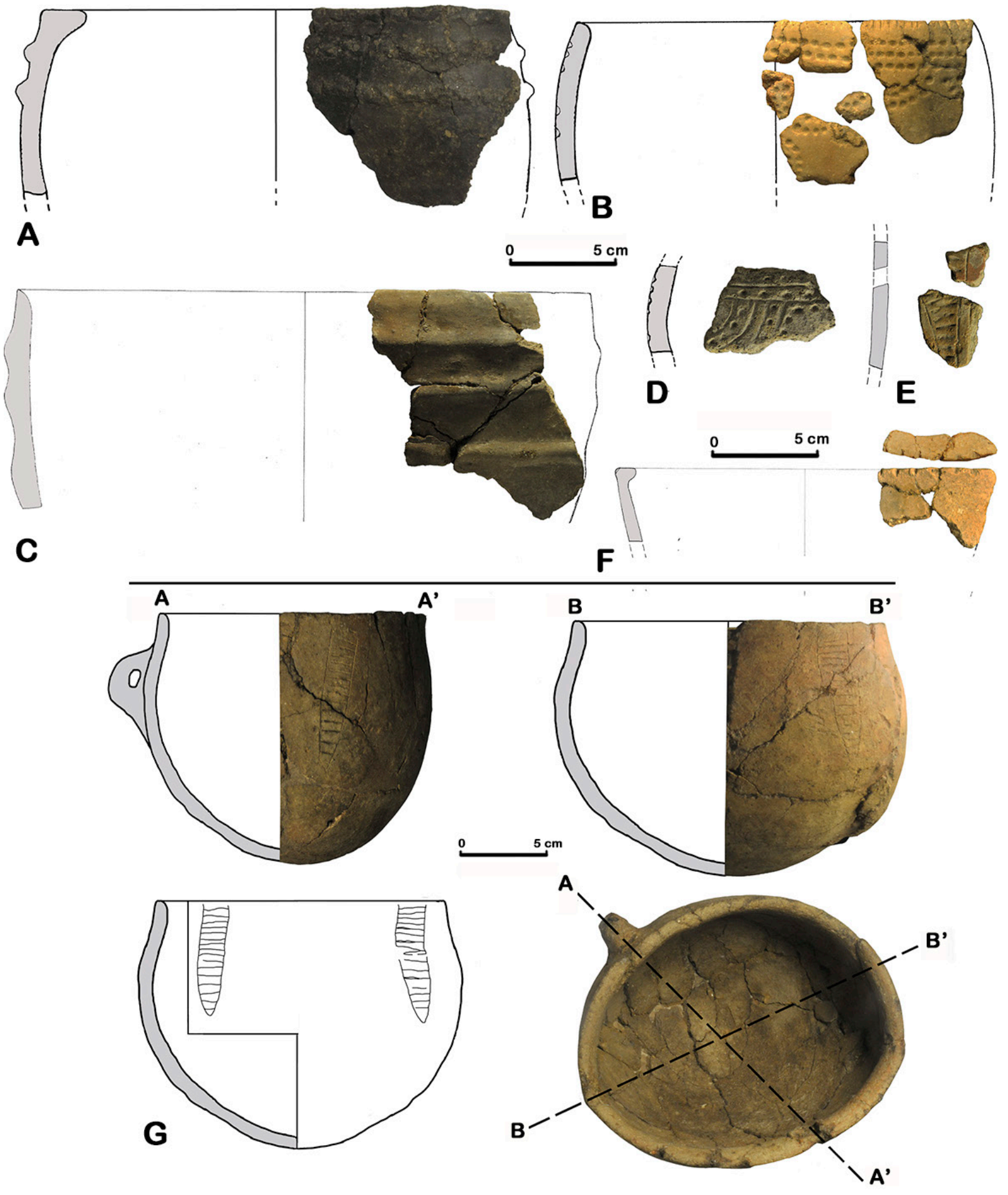

Fig. 5. Font del Ros (Berga, Barcelona), vasos cerámicos de estilo impreso-inciso: A. n. ${ }^{\circ} 23$ fosa E-28; B. n. ${ }^{\circ} 10$ fosa E-6; C. n. ${ }^{\circ} 12$ fosa E-1; D. n. ${ }^{\circ}$ 6, fosa E-6; E. n. ${ }^{\circ} 44$, fosa E-43; F. n. ${ }^{\circ} 29$ fosa E-33; G. n. ${ }^{\circ} 15$ fosa E-21. En color en la versión electrónica. 


\begin{tabular}{|l|c|c|}
\hline Motivos & n & \% \\
\hline A1 & 18 & 34,0 \\
\hline B1 & 4 & 7,5 \\
\hline B2 & 1 & 1,9 \\
\hline E1 & 2 & 3,8 \\
\hline F1 & 4 & 7,5 \\
\hline I1 & 17 & 32,1 \\
\hline I2 & 3 & 5,7 \\
\hline Total simples & 49 & 92,5 \\
\hline D3 & 1 & 1,9 \\
\hline D4 & 1 & 1,9 \\
\hline Compuesto (F1+D3) & 1 & 1,9 \\
\hline Figurativo & 1 & 1,9 \\
\hline Total complejos & 4 & 7,5 \\
\hline Total & 53 & 100 \\
\hline
\end{tabular}
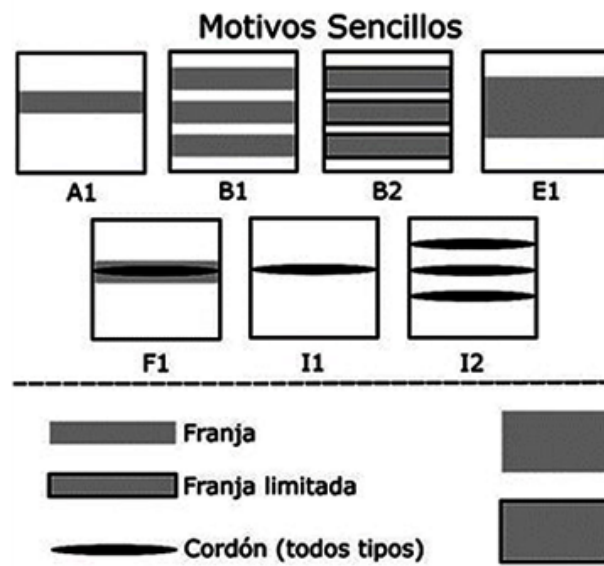

Motivos Complejos

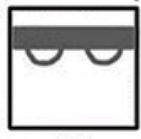

D3

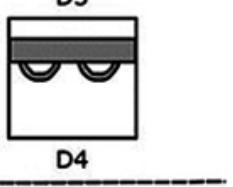

Franja ancha

Franja ancha limitada

Fig. 6. Font del Ros (Berga, Barcelona). Resumen tipos motivos decorativos sencillos y complejos (adaptado de Oms 2014).

publicadas como muestras sobre semillas carbonizadas (Bordas et al. 1996). En el informe del Laboratorio de Tucson-Arizona (AA) se identifican como carbones, siendo pertinente retener esta última atribución. Sin embargo, su validez temporal puede compararse con las nuevas fechas sobre semillas de cereal, determinadas a nivel taxonómico por Vicente López Morillas ${ }^{3}$ y tratadas en el Servicio de Datación por Radiocarbono de Sevilla
(CNA). Las fechas de las series AA y CNA se integran dentro del rango esperable para este período, aunque los $\delta$ de la serie AA derivan intervalos más amplios que los de la serie CNA (Tab. 4). Debido a su $\delta$ se ha excluido la fecha UBAR-186 (6980 \pm 390 BP) obtenida en el Suelo $\mathrm{N}$ en los años 80 y tratada en el Laboratorio de Radiocarbono de la Universidad de Barcelona. La serie se calibró con IntCal 20 a $2 \delta$ (Reimer et al. 2020) con OxCal v4.3.2 (C) Bronk Ramsey 2020).

3 Véase n. 2.

\begin{tabular}{|c|c|c|c|c|c|c|c|}
\hline Contexto & Muestra & \# Laboratorio & BP & $\boldsymbol{\delta}$ & \multicolumn{2}{|c|}{ Cal BC (p=95,4\%) } & Referencia \\
\hline SN & carbón & AA 16498 & 6561 & 56 & -5622 & -5385 & Bordas et al. 1996 \\
\hline E36 & carbón & AA 16502 & 6370 & 57 & -5474 & -5218 & Bordas et al. 1996 \\
\hline E32 & Hordeum vulgare & CNA 4935.1.2 & 6361 & 36 & -5471 & -5218 & Inédita \\
\hline E3 & Cerealea & CNA 4942.1.1 & 6354 & 38 & -5470 & -5217 & Inédita \\
\hline E33 & carbón & AA 16501 & 6307 & 68 & -5471 & -5065 & Bordas et al. 1996 \\
\hline E6 & Cerealea & CNA 4938.1.1 & 6289 & 38 & -5366 & -5218 & Inédita \\
\hline E44 & Hordeum vulgare & CNA 4943.1.1 & 6274 & 37 & -5326 & -5073 & Inédita \\
\hline E40 & Triticum dicoccum & CNA 4937.1.1 & 6272 & 37 & -5324 & -5073 & Inédita \\
\hline E42 & Hordeum vulgare & CNA 4939.1.1 & 6270 & 37 & -5322 & -5073 & Inédita \\
\hline E15 & carbón & AA 16499 & 6243 & 56 & -5323 & -5040 & Bordas et al. 1996 \\
\hline E39 & Hordeum vulgare & CNA 4944.1.1 & 6230 & 38 & -5306 & -5055 & Inédita \\
\hline E27 & Triticum dicoccum & CNA 4936.2.1 & 6190 & 35 & -5292 & -5032 & Inédita \\
\hline E21 & carbón & AA 16500 & 6058 & 79 & -5211 & -4788 & Bordas et al. 1996 \\
\hline
\end{tabular}

Tab. 4. Serie radiométrica C14 de Font del Ros. Intervalos calibrados (cal BC) a $2 \delta$ sg. IntCal 20 (Reimer et al. 2020) obtenidos con OxCal v4.3.2 (C) Bronk Ramsey 2020. 
El sumatorio de probabilidades advierte de una dispersión cronométrica con extremos entre $5600-4800 \mathrm{cal}$ $\mathrm{BC}$, acotada por las fechas sobre muestras de vida corta entre 5450-5050 cal BC. La fecha más antigua (AA 16498) y más reciente (AA 16500), ambas sobre carbón, se desvían de la serie que centra el rango máximo de probabilidades entre 5300-5200 cal BC, coherente con el desarrollo temporal del Neolítico Antiguo del nordeste de la península ibérica (Oms et al. 2016a) (Fig. 7).

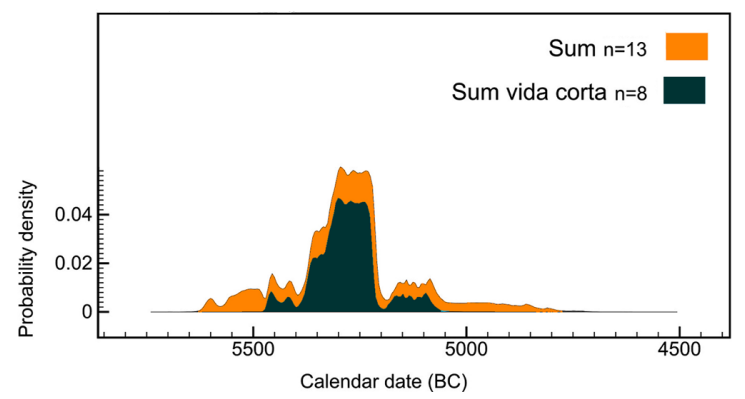

Fig. 7. Font del Ros (Berga, Barcelona). Distribución de probabilidades acumuladas de la serie de fechas completa y vida corta. Gráfico generado con OxCal v4.3.2 (C) Bronk Ramsey 2020. En color en la versión electrónica.

Aunque no se aprecian desviaciones significativas entre todas las fechas de la serie, el análisis cronométrico se centrará en los intervalos de las fechas sobre muestra de vida corta. Esta decisión obedece a las diferencias advertidas al comparar las series que combinan fechas sobre muestras de vida corta y vida larga, estas últimas suelen generar rangos temporales más antiguos, efecto conocido como "madera vieja". Además, en las muestras de vida corta se ha detectado que las fechas obtenidas sobre hueso de ovicáprido suelen ser más antiguas, a veces varios siglos, que las de semillas (Pardo-Gordó 2020). Ante estas divergencias, y admitiendo el interés de los rangos de las dataciones sobre carbón, para articular la cronometría de Font del Ros, se les ha considerado subsidiarios frente a los obtenidos a partir de semillas.

Las dataciones sobre vida corta conforman una serie temporalmente muy próxima. Para analizar esta tendencia se propone establecer agrupaciones a partir del rango numérico BP de las fechas aplicando PAST v.2 (Hammer et al. 2001). Este software establece asociaciones que representa por medio de diagramas relacionales. Su empleo en Font del Ros define un grupo 1 que asocia las fosas E-32, E-3. Las fosas E-6, E-44, E-40, E-42, E-15 y E-39 configuran un grupo 2, mientras E-27 aparece desconectada del resto (Fig. 8). Estos resultados son similares a los de la distribución de probabilidades al indicar que las fechas del grupo 2 coinciden con el intervalo de máxima probabilidad (Fig. 6).
La validez de las dataciones C14 pasa por justificar una estrecha relación entre fecha y contexto, extremo no siempre evidente (entre otros Bernabeu et al. 1999). En Font del Ros puede aceptarse que los intervalos de estas fechas cubren el rango temporal en el que los artefactos se asocian a esos contenedores (Tab. 4). Esta cuestión afecta a la resolución contextual de cada conjunto que puede analizarse a partir de atributos como los estilos decorativos detectados en las respectivas fosas.

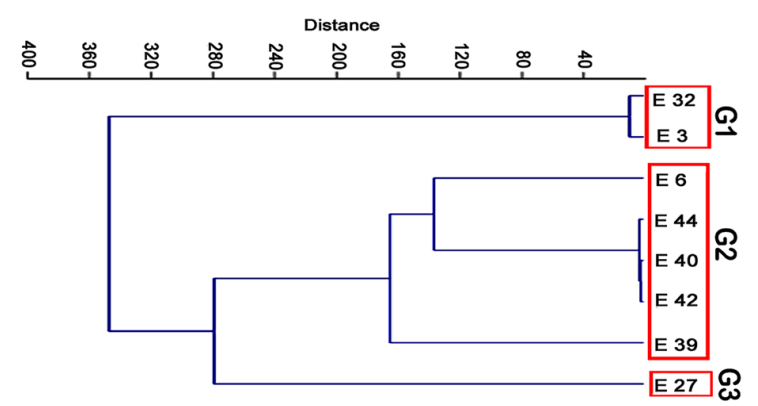

Fig. 8. Font del Ros (Berga, Barcelona). Agrupaciones de fosas establecidas a partir de PAST v.2 (Hammer et al. 2001). En color en la versión electrónica.

Otro condicionante relacionado con la interpretación de fechas con rangos similares son las incertidumbres cronométricas. Estas pueden mitigarse aplicando estadística bayesiana que calcula los rangos de mayor probabilidad del intervalo de calibración de cada fecha. Para acotar su dispersión temporal aplicamos un modelo bayesiano, en este caso a partir de las agrupaciones establecidas por PAST se ha construido un modelo secuencial de 3 fases (Bronk Ramsey 2009), con los rangos de los intervalos modelados a $2 \delta(\mathrm{Cal}$ $\mathrm{BC}$ modelado) según la aplicación OxCal v4.3.2 (C) Bronk Ramsey 2020) (Tab. 5, Fig. 9). A fin de facilitar la lectura de estos resultados, las franjas temporales se redondean respecto el rango decadal más próximo.

\section{DISCUSIÓN: FONT DEL ROS Y EL NEOLÍTICO ANTIGUO EN EL NORDESTE DE IBERIA}

Los estilos decorativos son un atributo central en la seriación de los conjuntos cerámicos. Al mismo tiempo, conforman códigos que representan conocimientos aceptados y transmitidos en el interior de un colectivo, por lo que cambios en esta esfera informan de posibles modificaciones en la organización sociocultural. $\mathrm{Su}$ aparición, desarrollo y desaparición deriva relaciones de orden temporal dentro de un yacimiento y establece conexiones por un extenso rango geográfico (Rigaud et al. 2018). Estas nociones que fundamentan el análisis 


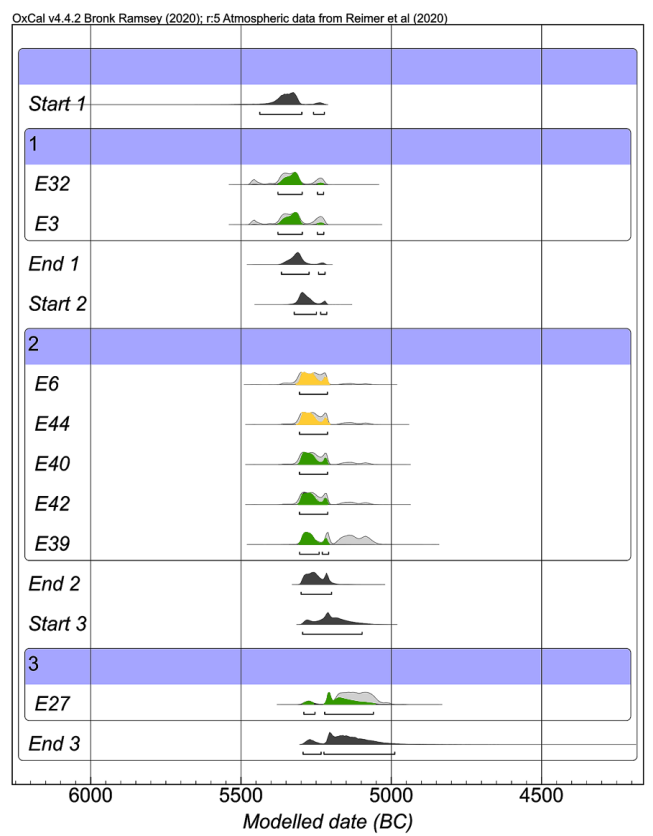

Fig. 9. Font del Ros (Berga, Barcelona), Modelado Bayesiano secuencial con 3 fases a partir de las muestras de vida corta. Fosas con cerámicas con decoración cardial e impreso-incisa. Gráfico generado por OxCal v4.3.2 (C) Bronk Ramsey 2020. En color en la versión electrónica. cronocultural permiten abordar la discusión de los estilos cerámicos identificados en Font del Ros, e integrar estos resultados en el desarrollo del Neolítico Antiguo del nordeste de la península ibérica.

\subsection{Estilos decorativos cerámicos: ¿qué tiempo, qué lugar?}

En el nordeste peninsular los estilos cardial e impreso-inciso -reconocidos en Font del Ros- vertebran el Neolítico Antiguo (Oms et al. 2016a). A modo de resumen, el estilo cardial se caracteriza por la alta presencia de decoración impresa por concha de bivalvo, acompañado por otras impresiones con instrumento simple y múltiple (peine o gradina) y cordones lisos. El estilo impreso-inciso, o epicardial, engloba una amplia gama de decoraciones destacando acanalados, incisiones, cordones y crestas con y sin decoración, sin embargo, la impresión cardial es escasa o nula (Bernabeu et al. 2011).

Para el estilo cardial se dispone de dataciones del Suelo N y en las fosas E-36, E-32, E-3, E-40, E-42, E-39 y E-27. El modelado bayesiano de las fechas sobre muestras de vida corta señala una fase inicial, indicada en E-32 y E-3 c. 5380-5230 cal BC, que continua entre $c$. 5310-5210 cal BC en E-40, E-42 y E-39. Este

\begin{tabular}{|c|c|c|c|c|c|c|c|c|c|c|}
\hline & & \multicolumn{3}{|c|}{$\begin{array}{l}\text { No modelado } \\
\text { (BC/AD) }\end{array}$} & \multicolumn{3}{|c|}{$\begin{array}{c}\text { Modelado } \\
\text { (BC/AD) }\end{array}$} & \multirow{2}{*}{$\begin{array}{c}\text { Indices } \\
\mathrm{A}_{\text {model }}=156.2 \\
\mathrm{~A}_{\text {overall }}=154.4 \\
\mathrm{~A}_{\text {comb }}\end{array}$} & \multirow[b]{2}{*}{ A } & \multirow[b]{2}{*}{$\mathrm{C}$} \\
\hline & & from & to & $\%$ & from & to & $\%$ & & & \\
\hline & Start 1 & & & & -5438 & -5223 & 95,5 & & & 98,5 \\
\hline \multicolumn{11}{|l|}{ Fase 1} \\
\hline & E32 & -5471 & -5218 & 95,4 & -5378 & -5226 & 95,4 & & 123,7 & 99,5 \\
\hline & E3 & -5470 & -5217 & 95,4 & -5378 & -5225 & 95,4 & & 131,5 & 99,5 \\
\hline & End 1 & & & & -5366 & -5221 & 95,4 & & & 99,7 \\
\hline & Start 2 & & & & -5324 & -5215 & 95,4 & & & 99,7 \\
\hline \multicolumn{11}{|l|}{ Fase 2} \\
\hline & E6 & -5366 & -5128 & 95,4 & -5306 & -5213 & 95,4 & & 113,8 & 99,6 \\
\hline & E44 & -5326 & -5073 & 95,4 & -5306 & -5213 & 95,4 & & 114,8 & 99,7 \\
\hline & E40 & -5325 & -5073 & 95,4 & -5306 & -5213 & 95,4 & & 115,6 & 99,7 \\
\hline & E42 & -5324 & -5073 & 95,4 & -5306 & -5212 & 95,4 & & 116,2 & 99,6 \\
\hline & E39 & -5306 & -5055 & 95,4 & -5306 & -5209 & 95,4 & & 116,1 & 99,6 \\
\hline & End 2 & & & & -5301 & -5199 & 95,4 & & & 99,3 \\
\hline & Start 3 & & & & -5296 & -5098 & 95,4 & & & 99,1 \\
\hline \multicolumn{11}{|l|}{ Fase 3} \\
\hline & E21 & -5292 & -5032 & 95,4 & -5292 & -5060 & 95,4 & & 90,3 & 99 \\
\hline & End 4 & & & & -5294 & -4989 & 95,4 & & & 96,6 \\
\hline
\end{tabular}

Tab. 5. Font del Ros (Berga, Barcelona). Modelado bayesiano secuencial con 3 fases sobre los grupos establecidos por PAST v.2 (Hammer et al. 2001). Los intervalos calibrados (cal BC) y calibrados modelados (cal BC modelado) se han obtenido con OxCal v4.3.2 (C) Bronk Ramsey 2020.

Trab. Prehist., 78, N. ${ }^{\circ}$ 2, julio-diciembre 2021, pp. 237-256, ISSN: 0082-5638 https://doi.org/10.3989/tp.2021.12274 
intervalo 5380-5210 cal BC E27 se podría extender hasta $5060 \mathrm{cal}$ BC (Fig. 9, Tab. 5), es ligeramente posterior pero concurrente con las fechas obtenidas en los yacimientos del prelitoral y litoral mediterráneo como Guixeres de Vilobí y Serreta (Oms et al. 2014), Cova Bonica y Can Sadurní (Edo et al. 2011), Toll y Can Roqueta (Oms et al. 2014), Sant Pau del Camp (Molist 2008), Cavet (Fontanals et al. 2008). Igualmente, E-27 encaja con las fechas obtenidas en La Draga (Palomo et al. 2014) y Cova de la Guineu (Oms et al. 2016c), atribuidos a un cardial "tardío".

El estilo impreso-inciso datado en las fosas E-33, E-6, E-44, E-15 y E-21, las fechas sobre muestras de vida corta de E-6 y E-44 lo posicionan en el intervalo c. 5310-5210 cal BC, aunque E-21 -sobre carbónadvierte de un dilatado rango (5211-4788 cal BC). En estos contextos no aparecen decoraciones atribuibles a la esfera cardial, pero son muy similares a las descritas en el Prepirineo de Huesca como el nivel 1a de Chaves (Baldellou 2011; Utrilla y Laborda 2018), La Puyascada (Baldellou 1987), Trocs (Rojo et al. 2013), Coro Trasito (Clemente et al. 2014); en el Prepirineo de Lleida en Cova Colomera (Oms et al. 2013), Cova del Foric, Cova Joan d'Os (Oms 2014), Parco (Petit 1996), Xicotó (Oms et al. 2019), fosa E-9 de Cova Gran de Santa Linya (Mora et al. 2011) y Margineda en el Pirineo axial (Guilaine y Martzluff 1995; Oms et al. 2016b). Este estilo señala la dispersión neolítica por el interior peninsular en La Revilla y La Lámpara (Soria) (Rojo et al. 2011a), La Vaquera (Segovia) (Rojo et al. 2011b) y Los Cascajos (Navarra) (García-Gazólaz et al. 2011).

La comparación de los componentes estilísticos cardial e impreso-inciso en Font del Ros con algunos conjuntos seleccionados del nordeste de la península ibérica visualiza dos áreas geográficas enraizadas en el litoral/prelitoral mediterráneo y el Prepirineo central (Fig. 10). Estos núcleos contienen agrupaciones de asentamientos próximos entre los que podrían circular productos y personas. Font del Ros aparece segregado por distancias entre $50-90 \mathrm{~km}$ respecto del núcleo cardial, y más de $100 \mathrm{~km}$ del Prepirineo central (Fig. 1B). Su desconexión respecto a esas zonas podría advertir de sitios no descubiertos, o indicar desplazamientos leap frog, aunque no de la magnitud a los propuestos en la dispersión del Neolítico por el interior peninsular (Rojo et al. 2018).

La posición temporal de estos estilos permite revisar la seriación decorativa establecida para el Neolítico Antiguo. En los últimos años se ha identificado un estilo anterior a la aparición del cardial, el estilo ligurimpreso, que advierte de un evento pionero anterior a $5600 \mathrm{cal} \mathrm{BC}$ presente en escasos sitios (Bernabeu et al. 2009; García Atienzar 2010; Martins et al. 2015), cuya presencia se restringe a dos enclaves del área central del Mediterráneo penínsular (Manen et al. 2019; sin embargo ver Pardo Gordó et al. 2021).

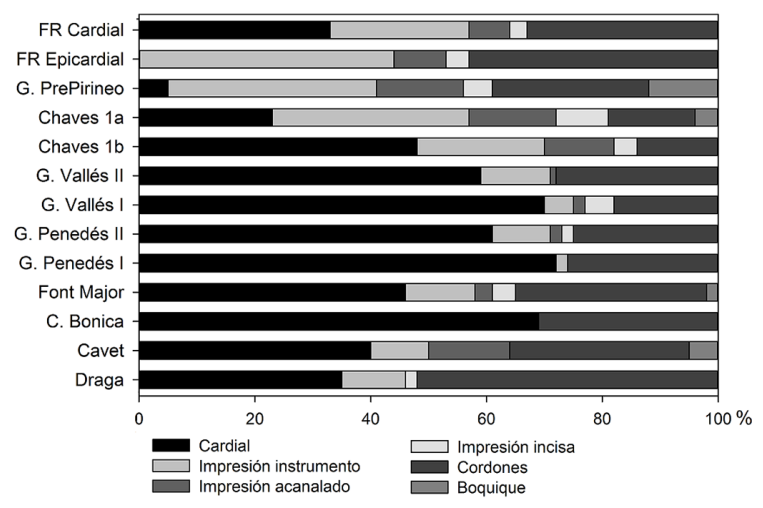

Fig. 10. Distribución porcentual de las decoraciones cerámicas simplificadas, de yacimientos de los ámbitos litoral y pirenaico (elaboración a partir de Oms 2017, Laborda 2019).

Este estilo no se identifica en Font del Ros. Allí el evento inicial se asocia con las fechas de E-32 y E-3, entre c. 5380-5230 cal BC, más reciente que el intervalo 5600-5370 cal BC derivado de la fecha sobre carbón del Suelo N (AA 16498). Este rango temporal que ejemplifica el efecto "madera vieja" (según Martins et al. 2015; Oms et al. 2016a) no será retenido en la discusión al carecer de fechas sobre muestras de vida corta de este contexto.

Sin embargo, entre 5380-5230 cal BC se advierten poblaciones neolíticas que practican la agricultura cerealista remontan desde la llanura del litoral/prelitoral -el área clásica cardial- el curso del río Llobregat hasta el pie del Prepirineo oriental, confirmando que durante el Neolítico los valles fluviales son una vía de penetración preferente de desplazamientos (Rojo et al. 2018). Las fechas de E-40, E-42 y E-39 indican que el estilo cardial y el asentamiento continúan entre $c$. 5310-5210 cal BC, cuando en las fosas E-6 y E-44 se detecta el estilo impreso-inciso. Las implicaciones que derivan de esta sincronía entre estilos se discuten a continuación.

Por otro lado, las fechas sobre muestra de vida corta de E-27 (5292-5060 cal BC) señalan la posible extensión temporal del estilo cardial, al igual que la fecha sobre carbón de E-21 (5211-4788 cal BC) atribuida al estilo impreso-inciso. Estas desviaciones pueden relacionarse con la oscilación de la curva de calibración IntCal 20 en el tramo 5200-5050 cal BC (Reimer et al. 2020), modulando la precisión de estos rangos temporales (Van Willigen 2004; Manen et al. 2018). La magnitud de las distorsiones provocadas por la curva de calibración se aprecia en algunas fechas de la serie como E-39 y E-27, y especialmente en E-21 que no se 
incluye en este modelo (Tab. 4). Como solución, asumimos la propuesta del modelo Bayesiano que ajusta E-27 dentro del intervalo concurrente establecido para la Fase 2 (Fig. 9, Tab. 5).

\subsection{Sincronía radiométrica y contemporaneidad de estilos decorativos}

Los intervalos definidos en Font del Ros son equiparables a los focos geoculturales cardial e impresoinciso. Con la salvedad del Suelo N, las fechas de las series AA y CNA proceden de fosas de pequeño volumen para las que se asume una estrecha relación entre contexto y fecha. Esto permite evaluar la extensión temporal y las posibles interacciones entre estos estilos (Pardo-Gordó et al. 2019). Estas dataciones se asocian a materiales procedentes de contextos en los que, excepto en E-33, no se identificó un uso prolongado, generados durante una escala temporal imprecisa. Ello afecta a la caracterización de cada fosa al no poder descartarse que, ante eventos próximos o sincrónicos, esos materiales puedan derivar de entidades culturales distintas.

El rango 5300-5210 cal BC -que interpola una sincronía radiométrica entre estilos que afecta a la caracterización cronocultural de esos conjuntos- permite reflexionar sobre si esos procesos que promueven la asociación de materiales responden a situaciones específicas y/o aleatorias difíciles de reconocer. Puede proponerse que estos estilos podrían aparecer mezclados de forma generalizada en un número significativo de contextos, asumiendo que los estilos decorativos cerámicos establecen relaciones de sincronía y/o diacronía y que las fosas atrapan materiales durante intervalos no necesariamente prolongados. Sin embargo, en los contenedores con cerámicas atribuidas al estilo cardial no se identifica la decoración impreso-inciso, y viceversa, excepto en E-15. Esto sugiere que estos estilos aparecen disociados en el asentamiento, como confirma nuestra revisión al señalar que corresponden a dos tradiciones distintas no relacionables entre sí (Bordas et al. 1996).

Las fosas se distribuyen por una extensa zona excavada sin ninguna organización espacial aparente, en el que 14 conjuntos se adscriben a la esfera cardial (15 con el Suelo N) y 10 al horizonte impreso-inciso (Bordas et al. 1996) (Fig. 11). En este estudio, las fosas con fechas e indicadores cerámicos ascienden a 11 de estilo cardial y 7 al estilo impreso-inciso. Las estimaciones son algo inferiores, pero no muy distintas, a las señaladas en el estudio original (Tab. 6).

Los condicionantes que llevan a la aparición de esos estilos en las fosas son difíciles de evaluar y la cercanía entre ellas no es necesariamente determinante. La decoración cardial de tres pequeños fragmentos muy rodados permite asignarlos a un solo vaso, el $\mathrm{n}^{\circ}$ 38 (Fig. 4C), proceden de las fosas E-39 y E-42, distantes más de $7 \mathrm{~m}$ pero con intervalos radiométricos similares (Fig. 9). Este ejemplo remite a la dificultad indicada de inferir los mecanismos de gestión y amortización de las fosas (Blanco González 2016).

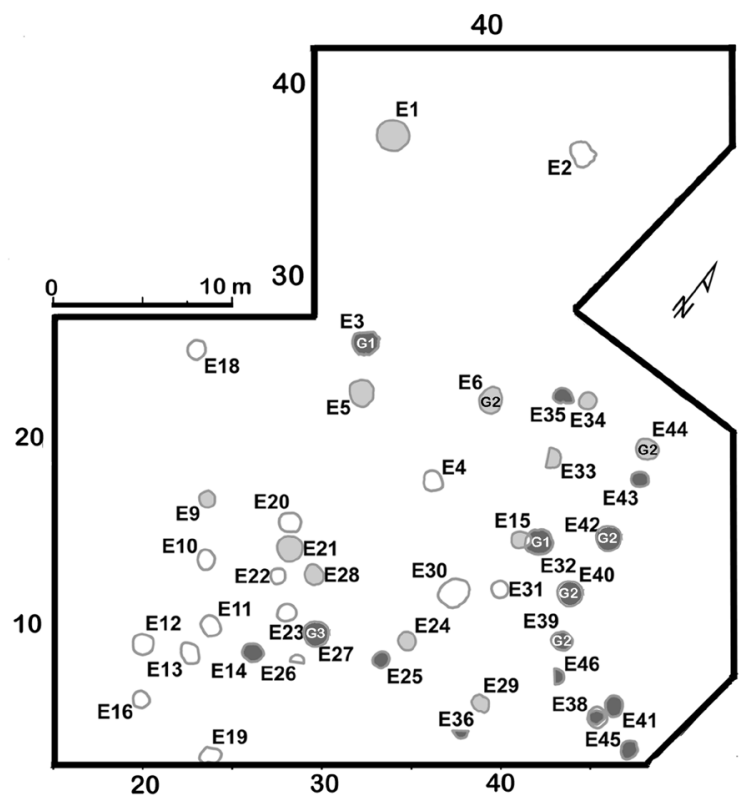

Fig. 11. Font del Ros (Berga, Barcelona). Fosas del sector sudeste $(\mathrm{X}=25-55 / \mathrm{Y}=0-30)$ indicando su asignación al estilo cardial e inciso-impreso (Bordas et al. 1996). Se señalan las fosas con datación radiométrica y su adscripción a los grupos establecidos por PAST v.2 (Hammer et al. 2001). En color en la versión electrónica.

\begin{tabular}{|c|c|c|}
\hline & Estilo cardial & $\begin{array}{c}\text { Estilo } \\
\text { impreso-inciso }\end{array}$ \\
\hline $\begin{array}{c}\text { Registro } \\
\text { cerámico y C14 }\end{array}$ & $\begin{array}{c}\text { Suelo Neolítico, } \\
\text { E-36, E-32, E-3, } \\
\text { E-40, E-42, E-39, } \\
\text { E-27 }\end{array}$ & $\begin{array}{c}\text { E-33, E-6, E-44, } \\
\text { E-15, E-21 }\end{array}$ \\
\hline $\begin{array}{c}\text { Registro } \\
\text { cerámico }\end{array}$ & E-25, E-38, E-43 & E-28, E-29 \\
\hline TOTAL & $\mathbf{1 1}$ & $\mathbf{7}$ \\
\hline
\end{tabular}

Tab. 6. Font del Ros (Berga, Barcelona). Contextos asignados a partir de restos cerámicos decorados datados por C14 AMS (vida corta y vida larga) y solo a partir del registro cerámico.

Bajo esta perspectiva, la coexistencia de ambos estilos en E-15 permitía examinar su posible asociación (Bordas et al. 1998), pero la revisión del conjunto no permitió que fuera confirmada. Una alternativa es considerar que E-15, que contiene cerámica asignada al estilo impreso-inciso, corta a la fosa E-32 de estilo 
cardial. Esa intersección pudo producir mezclas o trasvases entre los contenidos de las fosas (Fig. 11). Sin embargo, la fecha de E-32, 5380-5220 cal BC, confirma la anterioridad temporal del estilo cardial.

Otro vector temporal podría ser el cambio de cereales Triticum dicoccum y Hordeum vulgare identificados en 14 fosas, pero solo aparecen combinadas en E-40. Esta asociación se interpretó como resultado de pautas de cultivo y/o manipulación relacionadas con ciclos agrícolas temporalmente diferenciados (Pallarés et al. 1997). Esta inferencia es difícil de evaluar a partir de conjuntos carpológicos con pocas semillas, máxime cuando cebada y escanda aparecen en contextos atribuidos a las dos tradiciones cerámicas. Por otro lado, semillas e instrumental de molienda confirman la práctica de la agricultura cerealista en este sector del Prepirineo oriental c. 5400-5300 cal BC (Antolín et al. 2015).

\subsection{Cardial/Epicardial y la neolitización del nordeste de la península ibérica}

Los rangos temporales de los horizontes cardial $c$. $5600-4850$ cal BC y epicardial c. 4930-4420 cal BC articulan el desarrollo cronocultural del Neolítico Antiguo en el noreste de la península ibérica (Oms et al. 2016a). El origen del estilo cardial, en primera instancia se vincula con la irrupción por vía marítima de poblaciones alóctonas, inferencia criticada por Cruz Berrocal (2012). El estilo impreso-inciso, asimilado al horizonte epicardial, podría indicar distintas opciones: poblaciones autóctonas que imitan modelos cardiales (Martin et al. 2010), dos estilos contemporáneos (Van Willigen 1999, 2004), o una tradición neolitizante independiente que no discurre por el litoral, pero se rastrea por el sur de Francia y la península ibérica (Guilaine y Manen 2007; Perrin et al. 2018).

En la caracterización del estilo cardial en el noreste de la península ibérica es clave el registro de La Draga (Banyoles, Girona), por lo que podría ser interesante comparar sus tendencias estilísticas y cronométricas con las de Font del Ros. Los motivos decorativos de La Draga se relacionan significativamente con la tradición técnica cardial oblicuo (Bosch y Tarrús 2015), propia del Cardial Franco-Ibérico y con una extensa distribución por el litoral mediterráneo occidental (Van Willigen et al. 2010; Martín et al. 2010; Oms et al. 2014; Martins et al. 2015), es igualmente la técnica más común en el conjunto cardial de Font del Ros. En cambio, la esfera impreso-incisa de La Draga es definida como escasa y poco diagnóstica, contrastando con los referentes precisos de la zona del Prepirineo central que se reconocen en Font del Ros. Aunque algunas fechas se desvían ligeramente, la serie de fechas sobre muestras de vida corta posiciona a La Draga entre 5200-5000 cal BC (Palomo et al. 2014) mientras en Font del Ros remiten al intervalo 5380-5210 cal BC.

La comparación tiene un interés relativo ya que La Draga se atribuye a un momento "tardío" del estilo cardial, pero da pie a varias reflexiones. Confirma que Font del Ros se integra dentro de la esfera cardial detectada por el litoral/prelitoral mediterráneo del noreste de la península ibérica y, por tanto, indica su expansión hacia el interior, ampliando la distribución de este estilo (Fig. 10). Conjuntos de escasa entidad recuperados en Balma del Serrat del Pont y la Bofia de la Valldán en el Prepirineo oriental y en el nivel C3b de Margineda en el Pirineo axial (Oms et al. 2016b) parecen indicar una limitada progresión hacia el interior que contrasta con su entidad en el Prepirineo central en Forcas II y especialmente en Chaves (Laborda 2019). Esta radiación hacia el interior, entre 5500-5400 cal BC, señala que la tradición cardial se va escalonando en diversas zonas del litoral durante varios siglos, tal como confirma la serie radiométrica de La Draga.

La aparición del estilo impreso-inciso en Font del Ros c. 5310-5210 cal BC redefine la seriación cronocultural propuesta para el Neolítico Antiguo en el nordeste de la península ibérica, al subrayar que este horizonte no es posterior, se inserta dentro del desarrollo temporal del estilo cardial. La contemporaneidad entre 5000-4900 cal BC de los estilos cardial y epicardial (Oms et al. 2016a), más que definir tradiciones coetáneas, señala que ese solapamiento temporal es producto de la acumulación de probabilidades de las fechas finales e iniciales entre estos periodos. Sin embargo, la "tardía" cronología de La Draga y la irrupción del estilo impreso-inciso por el Prepirineo central hacia 5300 cal BC (Oms 2017; Rojo et al. 2018: tab. 7) visualizan un horizonte independiente y concurrente con la trayectoria temporal del estilo cardial durante el último tercio del VI milenio cal BC.

Este escenario no es exclusivo del nordeste de Iberia, y en el sudoeste de Francia se ha propuesto que esas tradiciones fueron contemporáneas (Van Willigen 1999, 2004). La reciente revisión del registro cronocultural de esta zona concluye que las semejanzas técnicas, estilísticas y el intercambio de artefactos definen dos grupos culturales independientes en parte contemporáneos, que podrían corresponder con tradiciones conectadas a nivel evolutivo o a entidades contemporáneas diferenciadas. La radiometría podría ayudar a dilucidar este interrogante, pero no es concluyente ya que las oscilaciones de la curva de calibración afectan el rango temporal cuando estas tradiciones podrían haber sido sincrónicas. Sin embargo, indicadores técnicos y contextuales como la transferencia de técnicas y artefactos argumentan a favor de su contemporaneidad durante el último tercio del VI milenio BC (Manen et al. 2018). 
Font del Ros precisa la incidencia de este factor sobre la sincronía radiométrica entre estos estilos, un fenómeno considerado determinante cuando se analizan las posibles interacciones entre estos horizontes en el sudeste de Francia. Este factor modula algunas dataciones, pero la mayoría de la serie radiométrica de la Fase 2 define un intervalo temporal sincrónico de orden centenario o inferior (Fig. 9) que, en último extremo, obedece a las características técnicas del laboratorio de datación donde se trataron las muestras. Este margen temporal parece excesivamente breve para identificar transformaciones técnicas y estilísticas que afilien las esferas cardial e impreso-incisa. En Font del Ros la disociación de estos estilos permite la adscripción precisa de los contextos a una de esas dos tradiciones, subrayando su desconexión, por lo que la sincronía radiométrica de estos estilos durante ese intervalo inferior a un siglo no implica su coexistencia. Alternativamente la irrupción del estilo impreso-inciso covaría con la sustitución del estilo cardial, sin que determine necesariamente su desaparición, y su trayectoria continua en otros enclaves.

\subsection{5,3-5,2 ka cal BC: ¿un segundo evento neolítico?}

La rápida sustitución del estilo cardial se ha señalado en otras zonas, siendo interesante la situación del Prepirineo central y oriental, cuya discusión está lastrada por el desigual registro cronométrico de la serie de yacimientos dispersos por una amplia zona geográfica ${ }^{4}$ (Oms et al. 2016b). Pese a estas limitaciones se propone que la distribución de probabilidades acumuladas de las fechas del estilo cardial c. 5600-5300 cal BC, se rarifica con la irrupción del estilo impreso-inciso, prevalente $c$. 5310-5210 cal BC. Pero la fecha 5300 cal BC se repite por toda la fachada litoral del Mediterráneo, área clásica del estilo cardial. En el nordeste se identifica una profunda "reorganización tecno-estilística", apareciendo técnicas y motivos decorativos que remiten al estilo impreso-inciso (Oms 2017). Más radical es la propuesta para la zona central donde se propone el "declive" cardial en favor del estilo incisoimpreso (Bernabeu et al. 2014). Estos cambios podrían expresar la influencia, directa o indirecta (transferencia de técnicas/intercambio de artefactos), desde la esfe-

\footnotetext{
${ }^{4}$ Los rangos temporales empleados para comparar la cronometría del estilo cardial en el Prepirineo oriental y central (Oms et al. 2016b) deben tomarse con cautela. La datación de Balma del Serrat del Pont se obtuvo sobre una falange de Sus scropha, no sobre un animal doméstico. En Chaves Ib se aprecian diferencias en el intervalo de la fecha sobre hueso de Ovis aries (GrA-38022) 200 años más antigua que otras 2 fechas concurrentes (sobre bellota y hueso de Ovis). Esta desviación afecta a la aparición del Neolítico en este sitio, coincide con las reservas expresadas al comparar fechas sobre distintos tipos de muestras (Pardo-Gordó 2020).
}

ra "epicardial” hacia la tradición clásica del litoral, en paralelo a la dispersión de un evento neolitizante que se registra por amplias zonas de la península ibérica (García Martínez de Lagrán 2015).

La asunción de que los indicadores de Font del Ros abogan por una rápida sustitución del estilo cardial en un intervalo inferior a la actual resolución del radiocarbono permite interrogar si la consolidación del Neolítico es un proceso monocausal, vinculado con el desarrollo de la zona litoral y con su expansión hacia el interior, visualizada a partir del estilo cardial. El estilo impreso-inciso conectado con una tradición que remite al Prepirineo central aparece en Font del Ros c. 5300$5210 \mathrm{cal} \mathrm{BC}$. Ese estilo advierte de la convivencia a lo largo del último tercio del VI milenio $\mathrm{BC}$ en el nordeste de la península ibérica de dos tradiciones decorativas que representan dos grupos culturales contemporáneos.

Este segundo evento, ligeramente posterior al señalado en el litoral, podría ingresar por rutas terrestres como el Prepirineo central, desempeñando un papel activo en el advenimiento del Neolítico por el interior (Utrilla et al. 1998; Rojo et al. 2018). Si se admite la concurrencia de estas entidades diferenciadas a partir de los estilos decorativos sería más apropiado considerar la consolidación del Neolítico en el nordeste peninsular como un proceso coalescente resultante de la interacción de diversas tradiciones culturales (Manen et al. 2018).

\section{CONCLUSIONES Y PERSPECTIVAS DE FUTURO}

La seriación cronocultural establecida para el Neolítico Antiguo en el nordeste de la península ibérica se articula a partir de dos horizontes decorativos: el estilo cardial c. 5560-4850 cal BC circunscrito principalmente al litoral mediterráneo, y el estilo impreso-inciso asimilado a la esfera Epicardial-c. 4930-4420 cal BC que se reconoce por el Prepirineo central (Oms et al. 2016a). Font del Ros, enclave del Prepirineo oriental sin aparente relación con estas áreas, registra diversos eventos que informan de la implantación del Neolítico durante el último tercio del VI milenio BC.

La sincronía radiométrica entre c. 5300-5220 cal $\mathrm{BC}$, reflejo de la posible contemporaneidad de estos estilos, asociada a la irrupción del estilo impreso-inciso, no es exclusiva de Font del Ros. Sin embargo, en este enclave se puede inferir la dificultad de establecer relaciones de filiación/evolución tecno-estilística respecto al estilo cardial. Alternativamente, la sustitución de estas tradiciones durante una centuria -o menos-, señala el límite actual de la resolución de las fechas de radiocarbono, durante el cual el estilo cardial es reemplazado relativamente. 
Otro factor que complica la definición de este evento es la incidencia de la oscilación 5200-5050 cal BC de la curva de calibración. Al distorsionar la precisión de las fechas de E-39, E-27, promueve la "continuidad" del estilo cardial tras $5200 \mathrm{cal} \mathrm{BC}$. Esta posibilidad es factible y se conocen enclaves con fechas similares que se atribuyen al cardial "tardío". El modelo Bayesiano despeja esta incertidumbre, ignorando estas desviaciones y primando los intervalos concurrentes con los definidos en la fase 2, con un aceptable margen de concordancia probabilística. Esta solución no se restringe a estas fechas al afectar a toda la serie cronométrica, como se aprecia en la repetición de los rangos numéricos de las fechas de los intervalos calibrados modelados temporalmente comprimidos (Tab. 5).

Estas observaciones afectan al interés de la aplicación de grandes bases cronométricas como la aproximación probabilística SCDPD, articuladas sobre un principio simple pero poderoso more people, more garbage, more garbage, more dates (Balsera et al. 2015), de las que derivan estimaciones de orden temporal que informan sobre tendencias de cambio demográfico y/o cultural. La capacidad explicativa de esas narrativas sobre la aparición y consolidación del Neolítico están afectadas por anomalías como la incidencia de las fluctuaciones de la curva de calibración o las discordancias temporales dependientes del tipo de muestra; sin olvidar la dificultad de evaluar la fiabilidad de la relación fecha/contexto de las dataciones que conforman estas bases de datos al combinar varios tipos de muestras con $\delta$ diversos

A lo largo del texto, es recurrente la cuestión de la idoneidad de asimilar estilos decorativos con entidades culturales que se refieren a colectivos humanos, una posición que podría calificarse como reduccionista. Un sistema cultural es producto de la interacción de múltiples componentes, no solo de escasos atributos seleccionados, como los motivos decorativos. Las actuales líneas de investigación que definen la diversidad genética de las poblaciones neolíticas seguramente permitirán reformular la noción "grupo cultural" de forma más precisa pudiendo establecer posibles interacciones entre grupos (Olalde et al. 2015; Szécsényi-Nagy et al. 2017).

Sin embargo, diversas lecturas derivan del recurso a los estilos decorativos como proxys de la trayectoria temporal de una manifestación vinculada con la identidad social e ideológica de un grupo. La irrupción del estilo impreso-inciso en Font del Ros en una escala temporal centenaria -o menor- genera una perspectiva distinta al analizar la consolidación del Neolítico en el nordeste de la península ibérica. Font del Ros confirma la dispersión de las poblaciones del litoral y su ulterior dispersión por el interior con la decoración cardial como icono. Esto ocurre entre 5380-5230 cal BC en paralelo a la aparición de la agricultura cerealista en las primeras estibaciones del Prepirineo oriental. En ese mismo espacio, c. 5300-5220 cal BC, irrumpe otra tradición neolitizante cuyos indicadores estilísticos remiten al Prepirineo central. Posiblemente, estas entidades tendrían un nivel organizativo y tecno-subsistencial semejante, siendo difíciles de diferenciar. Los estilos decorativos entendidos como códigos identitarios se convierten en un atributo privilegiado a la hora de identificar un proceso con una limitada visibilidad que responde a dos tradiciones similares, pero con trayectorias sociales y culturales distintas (Guilaine 2018).

Este esquema se parece al desarrollo propuesto para el Sudeste de Francia, donde Cardial y Epicardial configuran tradiciones independientes y contemporáneas durante parte del Neolítico Antiguo. Los nuevos contingentes identificados por el estilo impreso-inciso irrumpirían por rutas alternativas a la vía marítima. en un intervalo temporal posterior (300-200 años) al señalado en la zona del litoral (Utrilla et al. 1998). Según esta alternativa la implantación del Neolítico es un proceso coalescente en el que participan ambas tradiciones (Manen et al. 2018). Font del Ros aporta argumentos a este escenario dinámico donde pudieron producirse diferentes interacciones entre ambos grupos culturales implicados en la consolidación del Neolítico durante el último tercio del VI milenio $\mathrm{BC}$ en el nordeste de la península ibérica.

\section{AGRADECIMIENTOS}

Esta reflexión es deudora de las observaciones de las personas vinculadas con los trabajos iniciales en los años 90, en especial las de Ana Bordas y María Pallarés que advirtieron del interés de Font del Ros para caracterizar el Neolítico Antiguo en el nordeste de la península ibérica. Subrayamos en especial la implicación de Vicente López Morillas en este estudio. Los comentarios de dos revisores a este artículo han servido para reformular sus contenidos. Cualquier error debe imputarse exclusivamente a los autores.

\section{BIBLIOGRAFÍA}

Alday, A.: 2009: "El final del Mesolítico y los inicios del Neolítico en la Península Ibérica: Cronología y fases". Munibe Antropologia-Arkeologia 60:157-173.

Antolín, F. 2013: Of cereals, poppy, acorns and hazelnuts. Plant economy among early farmers $(5500-2300 \mathrm{cal} \mathrm{BC})$ in the NE of the Iberian Peninsula. An archaeobotanical approach. Tesis Doctoral. Universitat Autònoma de Barcelona. http://hdl.handle.net/10803/128997

Antolín, F.; Jacomet, S. y Buxó, R. 2015: "The hard knock life. Archaeobotanical data on farming practices during the Neolithic (5400 $2300 \mathrm{cal}$ BC) in the NE of the Iberian Peninsula". Journal of Archaeological Science 61: 90-104. https://doi.org/10.1016/j.jas.2015.05.007 
Ammerman, A. J. y Cavalli-Sforza, L. 1973: “A population model for the diffusion of early farming in Europe". En C. Renfrew (ed.): The explanation of culture change: models in prehistory. Duckworth. London: 343-357.

Baldellou, V. 1987: "Avance al estudio de la Espluga de la Puyascada". Bolskan 4: 3-42.

Baldellou, V. 2011: "La Cueva de Chaves (Bastarás, Huesca)". En J. Bernabéu, M. A. Rojo y Ll. Molina, Ll. (eds.): Las primeras producciones cerámicas: el VI milenio cal AC en la Península Ibérica. Saguntum PLAV extra-12, Universitat de València. Valencia: 141-144.

Balsera, V.; Díaz-del-Río, P.; Gilman, A.; Uriarte, A. y Vicent, J. M. 2015: "Approaching the demography of late prehistoric Iberia through summed calibrated date probability distributions (7000-2000 cal BC)". Quaternary International 386: 208-211. https://doi.org/10.1016/j.quaint.2015.06.022

Bernabeu, J. 1989: La tradición cultural de las cerámicas impresas en la zona oriental de la Península Ibérica. Servicio de Investigación Prehistórica, serie Trabajos Varios 86, Diputación Provincial. Valencia.

Bernabeu, J. 1996: "Indigenismo y migracionismo. Aspectos de la neolitización en la fachada oriental de la Península Ibérica”. Trabajos de Prehistoria 53 (2): 37-54. https://doi.org/10.3989/tp.1996.v53.i2.391

Bernabeu, J.; Pérez Ripoll, M. y Martínez Valle, R. 1999: "Huesos, neolitización y contextos arqueológicos aparentes". II Congrés Neolitic de la Península Ibérica (Valencia 1999). Saguntum PLAV extra-2. Universitat de València. Valencia: 589-596.

Bernabeu, J.; García Puchol, O.; Pardo-Gordó, S.; Barton, C. M. y McClure, S. B. 2014: "Socioecological dynamics at the time of Neolithic transition in Iberia". Environmental Archaeology 19: 214-225. https://doi.org/10.1179/1749631414Y.0000000032

Bernabeu J.; Molina, L.; Esquembre Bebia, M.; Ortega, J. y Boronat Soler, J. 2009: "La cerámica impresa en el origen del Neolítico en la Península Ibérica”. En De Méditerranée et d'ailleurs... Mélanges offerts a Jean Guilaine. Les Archives d'Écologie Préhistorique. Toulouse: 83-95.

Bernabéu, J.; Rojo, M. A. y Molina, Ll. (eds.) 2011: Las primeras producciones cerámicas: el VI milenio cal AC en la Península Ibérica. Saguntum PLAV extra-12. Universitat de València. Valencia.

Blanco González, A. 2016: "Microhistorias de la Prehistoria Reciente en el interior de la Península Ibérica". Trabajos de Prehistoria 73 (1): 47-67. https://doi.org/10.3989/tp.2016.12163

Bordas, A.; Mora, R. y López, V. 1996: "El asentamiento al aire libre del Neolítico antiguo en la Font del Ros (Berga, Berguedà)". I Congrés del Neolític a la Península Ibérica (Bellaterra-Gava 1995): 397-403.

Bordes, F 1975. "Sur la notion de sol d'habitat en préhistoire paléolithique". Bulletin de la Société Préhistorique Française 72 (5): 139144. https://doi.org/10.3406/bspf.1975.8367

Bosch, A. y Tarrús, J. 2015: "La Draga. Una aproximación al estilo decorativo". En V. Gonçalves, M. Diniz y A. Sousa (eds.): Actas 5. Congresso do Neolítico Peninsular (Lisboa 2011): 482-487. Lisboa.

Bronk Ramsey C. 2009: "Bayesian analysis of radiocarbon dates". Radiocarbon 51: 337-360. https://doi.org/10.1017/s0033822200033865

Clemente Conte, I.; Gassiot Ballbè, E.; Rey Lanaspa, J; Mazzucco, N. y Obea Gómez, L. 2014: “'Cort o Transito'-Coro Trasito- o corral de tránsito: una cueva pastoril del Neolítico Antiguo en el corazón de Sobrarbe". En I. Clemente Conte, E. Gassiot Ballbè y J. Rey Lanaspa (eds.): Sobrarbe antes de Sobrarbe: pinceladas de historia de los Pirineos. Centro de Estudios de Sobrarbe. Zaragoza: 11-32.

Cruz Berrocal, M. 2012: "The Early Neolithic in the Iberian Peninsula and the Western Mediterranean: a review of the evidence on migration". Journal of World Prehistory 25: 123-156. https://doi.org/10.1007/s10963-012-9059-9

Edo, M.; Blasco, A. y Villalba, M. J. (eds.) 2011: La Cova de Can Sadurní i la Prehistòria de Garraf. Recull de 30 anys d'Investigació. Ed. EDAR. Milán.

Fontanals, M.; Euba, I.; Morales, J. I.; Oms, F. X. y Vergès, J. M. 2008: "El asentamiento litoral al aire libre de El Cavet (Cambrils, Tarragona)". En M. Hernández, J. Soler y J. López Padilla (eds.): Actas del IV Congreso del Neolítico Peninsular (Alicante 2006): 168-175. Alicante.

García Atiénzar, J. 2010: "Las comarcas centromeridionales valencianas en el contexto de la Neolitización de la fachada norocci- dental del Mediterráneo". Trabajos de Prehistoria 67 (1): 37-58. https://doi.org/10.3989/tp.2010.10030

Garcia Borja, P. 2017: Las cerámicas neolíticas de la Cova de la Sarsa (Bocairent, Valencia). Servicio de Investigación Prehistórica, serie Trabajos Varios 120, Diputación Provincial. Valencia.

García-Gazólaz, J.; Sesma Sesma,J.; Rojo Guerra, M.; Alday Ruiz, A.; Garrido Pena, R. y García Martínez de Lagrán, I. 2011: "Los Cascajos (Los Arcos, Navarra)”. En J. Bernabéu, M. A. Rojo y L1. Molina (eds.): Las primeras producciones cerámicas: el VI milenio cal AC en la Península Ibérica. Saguntum PLAV extra-12, Universitat de València. Valencia: 135-140.

García Martínez de Lagrán, I. 2015: "Recent data and approaches on the Neolithization of the Iberian Peninsula". European Journal of Archaeology 18 (3): 429-453. https://doi.org/10.1179/1461957114Y.0000000084

García Martínez de Lagrán, I. 2018: "Review of the archaeological contexts and theoretical models of the Neolithisation of Spain: The North Meseta, the Ebro valley and Catalonia as a case study". Quaternary International 472: 172-194. https://doi.org/10.1016/j.quaint.2016.12.043

García Martínez de Lagrán, I.; Garrido, R.; Rojo, M.; Alday, A.; García Gazólaz, J. y Sesma, J. 2011: “Cerámicas, estilo y neolitización: estudio comparativo de algunos ejemplos de la Meseta norte y Alto valle del Ebro". En J. Bernabéu, M. A. Rojo y Ll. Molina (eds.): Las primeras producciones cerámicas: el VI milenio cal $A C$ en la Península Ibérica. Saguntum PLAV extra-12, Universitat de València. Valencia: 83-104.

García-Puchol, O; Bernabeu, J.; Barton, M.; Pardo, S.; McClure, B. y Diez, A. 2018: "A Bayesian approach for timing the Neolithization in Mediterranean Iberia”. Radiocarbon 60: 181-205. https://doi.org/10.1017/rdc.2017.61

Gómez Pérez, G. 2011: "La técnica cardial y su variabilidad formal". En J. Bernabéu, M. A. Rojo y Ll. Molina (eds.): Las primeras producciones cerámicas: el VI milenio cal AC en la Península Ibérica. Saguntum PLAV extra-12, Universitat de València. Valencia: 153-178.

Guilaine, J. 2018: "A personal view of the Neolithisation of the Western Mediterranean”. Quaternary International 470: 211-225. https://doi.org/10.1016/j.quaint.2017.06.019

Guilaine, J. y Manen, C. 2007: "From Mesolithic to Early Neolithic in Western Mediterranean". Proceedings of the British Academy 144 21-51. https://doi.org/10.5871/bacad/9780197264140.003.0003

Guilaine, J. y Martzluff, M. 1995: Les excavacions a la Balma de la Margineda (1979-1991). Sèrie Prehistòria d'Andorra, Andorra.

Hammer, Ø.; Harper, D. y Ryan, P. 2001: "PAST: Paleontological Statistics Software Package for education and data analysis". Palaeontologia Electronica 4. https://palaeoelectronica.org/2001.htm (consulta 01-06-2021).

Isern, N.; Zilhão, J.; Fort, J. y Ammerman, A. 2017: "Modeling the role of voyaging in the coastal spread of the Early Neolithic in the West Mediterranean". Proceedings of the National Academy of Sciences 114: 897-902. https://doi.org/10.1073/pnas.1613413114

Jiménez Guijarro, J. 2010: Cazadores y campesinos: la neolitización del interior de la Península Ibérica. Real Academia de la Historia. Madrid

Jordá Pardo, J. F.; Piqué, R. y Mora, R. 1992: "La secuencia litoestratigráfica y arqueológica del yacimiento de la Font del Ros (Berga, Barcelona)". Cuaternario y Geomorfología 6: 21-30.

Jover Maestre, F. y García Atiénzar, G. 2014: "Sobre la neolitización de los grupos mesolíticos en el este de la Península Ibérica: la exclusión como posibilidad". Pyrenae 45: 55-88.

Jover Maestre, F.; Pastor Quiles, M. y Torregrosa Giménez, P. 2019: “Advances in the analysis of households in the early neolithic groups of the Iberian Peninsula: deciphering a partial archaeological record". Journal of Anthropological Archaeology 53: 1-21. https://doi.org/10.1016/j.jaa.2018.10.001

Laborda, R. 2019: El Neolítico Antiguo en el valle medio del Ebro. Una visión desde la cerámica y las dataciones radiocarbónicas. Monografías Arqueológicas 55, Prensas de la Universidad de Zaragoza. Zaragoza.

Lapuente, P. e Igea, J. 2014: "Estudio petrológico de las cerámicas neolíticas de Forcas II y otros yacimientos del entorno". En P. Utrilla,

Trab. Prehist., 78, N. ${ }^{\circ} 2$, julio-diciembre 2021, pp. 237-256, ISSN: 0082-5638

https://doi.org/10.3989/tp.2021.12274 
C. Mazo (eds.): La Peña de las Forcas (Graus, Huesca). Un asentamiento estratégico en la confluencia del Ésera y el Isábena. Monografías Arqueológicas. Prehistoria 46, Universidad de Zaragoza. Zaragoza: 267-283.

Manen, C. 2002: "Structure et identité des styles céramiques du Néolithique ancien entre Rhône et Èbre". Gallia Préhistoire 44: 121-166. https://doi.org/10.3406/galip.2002.2033

Manen, C.; Perrin, T.; Guilaine, J.; Bouby, L.; Bréhard, S.; Briois, F.... y Vigne, J. D. 2018: "The Neolithic transition in the Western Mediterranean: a complex and non-linear diffusion process". Radiocarbon 61: 531-571. https://doi.org/10.1017/RDC.2018.98

Manen, C. ; Perrin, T.; Raux, A.; Binder, D.; Le Bourdonnec, F.; Briois, F... y Queffelec, A. 2019: "Le sommet de l'iceberg? Colonisation pionnière et néolithisation de la France méditerranéenne”. Bulletin de la Société préhistorique française 116 : 317-361.

Martín, A. ; Edo, M.; Tarrús, J. y Clop, X. 2010: "Le Néolithique ancien de Catalogne (VIe- première moitié du Ve millénaire av. J. C.)". En C. Manen, F. Convertini, D. Binder e I. Sénépart (eds.): Premières sociétés paysannes de Méditerranée occidentale. Structure des productions céramiques. Mémoires de la Société préhistorique française 51. Paris: 197-214.

Martínez-Grau, H; Morell-Rovira, B. y Antolín, F. 2021: "Radiocarbon dates associated to Neolithic contexts (ca. 5900 - 2000 Cal BC) from the Northwestern Mediterranean Arch to the High Rhine Area". Journal of Open Archaeology Data 9, 1: 1-10. https://doi. org/10.5334/joad.72

Martínez-Moreno, J.; Mora, R. y Casanova, J. 2006: "El contexto cronométrico y tecno-tipológico durante el Tardiglaciar y Postglaciar de la vertiente sur de los Pirineos orientales". Revista d'Arqueologia de Ponent 16-17: 7-44.

Martins, H.; Oms, F. X.; Pereira, L.; Pike, A. W.; Rowsell, K. y Zilhão, J. 2015: "Radiocarbon dating the beginning of the Neolithic in Iberia: new results, new problems". Journal of Mediterranean Archaeology 28: 105-131. https://doi.org/10.1558/jmea.v28i1.27503

Molist, M. (coord.) 2008: "El jaciment de la Caserna de Sant Pau del Camp: aproximació a la caracterització d'un assentament del neolític antic". Quarhis 04: 13-87.

Mora, R.; Benito -Calvo, A.; Martínez -Moreno, J.; González Marcén, P. y Torre Sainz, I. de la 2011: "Chrono -stratigraphy of the Upper Pleistocene and Holocene archaeological sequence in Cova Gran (South -eastern Pre -Pyrenees, Iberian Peninsula)". Journal of Quaternary Science 26 (6): 635-644. https://doi.org/10.1002/jqs. 1486

Moral del Hoyo, S. y Cebrià, A. 2006: "La cerámica cardial y sus imitaciones en la cuenca del Duero y el Alto Ebro". Veleia 23: 9-23.

Olalde, I.; Schroeder, H.; Sandoval-Velasco, M.; Vinner, L.; Lobón, I.; Ramírez, O... y Lalueza-Fox, C. 2015: “A common genetic origin for early farmers of the Western Mediterranean Cardial and the Central European LBK cultures". Molecular Biology and Evolution 32: 3132-3142. https://doi.org/10.1093/molbev/msv181

Oms, F. X. 2014: La Neolitització del Nord-Est de la Península Ibèrica a partir de les Datacions de ${ }^{14} \mathrm{C}$ i les Primeres Ceràmiques Impreses c.5600-4900 cal BC. Tesis doctoral. Universidad de Barcelona. http://hdl.handle.net/10803/353618

Oms, F. X. 2017: "Fases y territorios de la neolitización del NE de la Península Ibérica ca. 5600-4900 cal BC". Munibe Antropologia-Arkeologia 67: 155-177. https://doi.org/10.21630/maa.2017.68.01

Oms, F. X.; Esteve, X.; Mestres, J.; Martín, P. y Martins, H. 2014: "La neolitización del nordeste de la Península Ibérica: datos radiocarbónicos y culturales de los asentamientos al aire libre del Penedès". Trabajos de Prehistoria 71 (1): 43-56.

https://doi.org/10.3989/tp.2014.12123

Oms, F. X.; López-García, J. M.; Mangado, X.; Martín, P.; Mendiela, S.; Morales, J. I.... y Yubero, M. 2013: "Hàbitat en cova i espai pels ramats ca. 6200- 6000 BP: La Cova Colomera durant el neolític antic". Saguntum. PLAV 45: 25-38.

Oms, F. X.; Martín, A.; Esteve, X.; Mestres, J.; Morell, B.; Subirà, E. y Gibaja, J 2016a: "The Neolithic in northeast Iberia: chronocultural phases and ${ }^{14} \mathrm{C}$ ". Radiocarbon 58: 291-309. https://doi.org/10.1017/rdc.2015.14

Oms, F. X.; Gibaja, J. F.; Mazzucco, N. y Guilaine, J. 2016b: "Revisión radiocarbónica y cronocultural del Neolítico antiguo de la Balma
Margineda (Aixovall, Andorra)". Trabajos de Prehistoria 73(1): 2946. https://doi.org/10.3989/tp.2016.12162

Oms, F. X.; Mestres, J.; Cebrià, A.; Morales, J. I.; Nadal, J.; Pedro, M.; Mendiela, S. y Martín P. 2016c: "La cova de la Guineu (Font-Rubí, Barcelona) i les relacions plana-muntanya al Penedès durant el neolític inicial. Del neolític a l'edat del bronze en el Mediterrani occidental". SIP Trabajos Varios 119: 97-107.

Oms, F. X.; Sánchez de la Torre, M.; Petit, M. A. López-Cachero, F. J. y Mangado, X. 2019: "Nuevos datos del VI y V milenio cal BC en el llano y Prepirineo de Lleida (NE de la Península Ibérica): el Abric del Xicotó y Les Auvelles". Munibe Antropologia-Arkeologia 70: 93107. https://doi.org/10.21630/maa.2019.70.05

Pallarés, M.; Bordas, A. y Mora, R. 1997: "El proceso de neolitización en los Pirineos Orientales. Un modelo de continuidad entre los cazadores-recolectores neolíticos y los primeros grupos agropastoriles". Trabajos de Prehistoria 54 (1): 121-141. https://doi.org/10.3989/tp.1997.v54.i1.382

Palomo, A.; Piqué, R.; Terradas, X.; Bosch, A.; Buxó, R.; Chinchilla, J.... y Tarrús, J. 2014: "Prehistoric occupation of Banyoles lakeshore: Results of recent excavations at La Draga site, Girona, Spain”. Journal of Wetland Archaeology 14: 58-73. https://doi.org/10.1179/1473297114Z.00000000010

Pardo-Gordó, S. 2020: “Efecto de los huesos de ovicaprinos domésticos en las fechas radiocarbónicas?". Archivo de Prehistoria Levantina 33: 55-76.

Pardo-Gordó, S.; García Puchol, O.; Bernabeu, J. y Díez Castillo, A. 2019: "Timing the Mesolithic- Neolithic Transition in the Iberian Peninsula: the radiocarbon dataset". Journal of Open Archaeology Data 7:4. https://doi.org/10.5334/joad.49

Pardo-Gordo, S.; Gómez-Bach, A.; Molist. M. y Bernabeu Auban, J. (eds). 2021: Contextualizando la cerámica impressa: Horizontes culturales en la península Iberica. Universitat Autònoma de Barcelona. Barcelona.

Perrin, T.; Manen, C.; Valdeyron, N. y Guilaine, J. 2018: "Beyond the sea. The Neolithic transition in the southwest of France". Quaternary International 470: 318-332. https://doi.org/10.1016/j.quaint.2017.05.027

Petit, M. A (ed.) 1996: El procès de neolitització de la Vall del Segre: cova del Parco (Alòs de Balaguer, La Noguera). Ed. Seminari d'Estudis i Recerques Préhistoriques Monografies 1, Universitat de Barcelona. Barcelona

Prats, G.; Antolín, F. y Alonso, N. 2020: "Household storage, surplus and supra-household storage in prehistoric and protohistoric societies of the Western Mediterranean". PLoS ONE 15(9): e0238237. https://doi.org/10.1371/journal.pone.0238237

Reimer, P., Austin, W., Bard, E., Bayliss, A., Blackwell, P., Bronk Ramsey, C.... y Talamo, S. 2020: "The IntCal20 Northern Hemisphere Radiocarbon Age Calibration Curve (0-55 cal kBP)". Radiocarbon 62: 725-757. https://doi.org/10.1017/rdc.2020.41

Rigaud, S.; Manen, C. y García-Martínez de Lagrán, I. 2018: "Symbols in motion: flexible cultural boundaries and the fast spread of the Neolithic in the western Mediterranean". PLOS ONE 13(5): e0196488. https://doi.org/10.1371/journal.pone.0196488

Roda Gilabert, X.; Martínez-Moreno, J. y Mora Torcal, R. 2016: “Ground stone tools and spatial organization at the Mesolithic site of Font del Ros (Southeastern Pre-Pyrenees, Spain". Journal of Archaeological Science: Reports 5: 209-224. https://doi.org/10.1016/j.jasrep.2015.11.023

Roda Gilabert, X.; Roy Sunyer, M.; Griera Roca, R.; Vega, S.; Plasencia Figueroa, J.; Martínez-Moreno, J. y Mora R. 2018: "Fora de la norma? Mesolític i Neolític antic de la Font del Ros". IV Jornades d'Arqueologia de la Catalunya Central (Solsona 2016): 31-37.

Rojo, M.; Kunst, M.; Garrido, R. y García Martínez de Lagrán, I. 2006: "La neolitización de la Meseta Norte a la luz del C-14: análisis de 47 dataciones absolutas inéditas de dos yacimientos domésticos del Valle de Ambrona (Soria, España)". Archivo de Prehistoria Levantina XXVI: 39-100.

Rojo, M.; Peña-Chocarro, L.; Royo, J. I.; Tejedor, C.; García-Martínez de Lagrán, I.; Arcusa-Magallón, H.... y Alt, K. W. 2013: "Pastores trashumantes del Neolítico antiguo en un entorno de alta montaña: secuencia cronocultural de la Cova de Els Trocs (San Feliú de Veri, 
Huesca)". Boletin del Seminario de Estudios de Arte y Arqueología 79: $9-55$.

Rojo, M.; Garrido, R.; García Martínez de Lagrán, I.; Alday, A.; García Gazólaz, J. y Sesma, J. 2011a: "El Valle de Ambrona y la provincia de Soria: La Lámpara, La Revilla del Campo y El Abrigo de la Dehesa/ Carlos Álvarez". En J. Bernabéu, M. A. Rojo y Ll. Molina (eds.): Las primeras producciones cerámicas: el VI milenio cal AC en la Península Ibérica. Saguntum PLAV extra-12, Universitat de València. Valencia: $105-108$

Rojo, M.; Garrido, R.; García Martínez de Lagrán, I.; Alday, A.; García Gazólaz, J. y Sesma, J. 2011b: La Cueva de la Vaquera (Torreiglesias, Segovia)". En J. Bernabéu, M. A. Rojo y L1. Molina, L1. (eds.): Las primeras producciones cerámicas: el VI milenio cal $A C$ en la Península Ibérica. Saguntum PLAV extra-12, Universitat de València. Valencia: 109-111.

Rojo, M.; García-Martínez de Lagrán, I. y Royo-Guillén, J. 2018: “The beginning of the Neolithic in the mid-Ebro valley and in Iberia's Inland (Northern and Southern submeseta), Spain". Quaternary International 470: 398-438. https://doi.org/10.1016/j.quaint.2017.12.037

Szécsényi-Nagy, A.; Roth, C.; Brandt, G.; Rihuete-Herrada, C.; TejedorRodríguez, C.; Held, P.... y Alt, K. W. 2017: "The maternal genetic make-up of the Iberian Peninsula between the Neolithic and the Early Bronze Age". Scientific Reports 7: 15644. https://doi.org/10.1038/s41598-017-15480-9

Utrilla, P.; Cava, A.; Alday, A.; Baldellou, V.; Barandiarán, I.; Mazo, C. y Montes, L. 1998: "Le passage du mésolithique au néolithique ancien dans le Bassin de l'Ebre (Espagne) d'après les datations C14". Préhistoire Européenne 12: 171-194.

Utrilla, P. y Laborda, R. 2018: "La Cueva de Chaves (Bastarás, Huesca): 15000 años de ocupación prehistórica". Trabajos de Prehistoria 75 (2): 248-269. https://doi.org/10.3989/tp.2018.12214

Van Willigen, S. 1999: "L'Epicardial et la Néolithisation de la France méditerranéenne". II Congrés Neolític de la Península Ibérica (Valencia 1999). Saguntum extra-2, Universitat de València. Valencia: 571-581.

Van Willigen, S. 2004: "Aspects culturels de la néolithisation en Méditerranée occidentale: le Cardial et 1'Epicardial'. Bulletin de la Société Préhistorique Française 101 (3): 463-495. https://doi.org/10.3406/bspf.2004.13028

Van Willigen, S.; Hajdas, I. y Bonani, G. 2010: "La chronologie du groupe Bas-Rhône-Provence du cardial franco-ibérique". En C. Manen, F. Convertini, D. Binder e I. Sénépart (eds.): Premières sociétés paysannes de Méditerranée occidentale. Structure des productions céramiques. Mémoires de la Société Préhistorique Française 51. Paris: 169-178.

Zilhão, J. 1997: "Maritime pioneer colonization in the Early Neolithic of the West Mediterranean. Testing the model against the evidence". Documenta Praehistorica XXIV: 19-42.

Zilhão, J. 2001: "Radiocarbon evidence for maritime pioneer colonization at the origins of farming in west Mediterranean Europe". Proceedings of the National Academy of Sciences 98: 14180-14185. https://doi.org/10.1073/pnas.241522898

Trab. Prehist., 78, N. ${ }^{\circ}$ 2, julio-diciembre 2021, pp. 237-256, ISSN: 0082-5638

https://doi.org/10.3989/tp.2021.12274 